\title{
LOS ATAQUES ARMADOS CON DRONES EN DERECHO INTERNACIONAL*
}

\author{
Felipe Gómez IsA \\ Profesor Titular de Derecho Internacional Público \\ Universidad de Deusto
}

SUMARIO: 1. INTRODUCCIÓN.-2. LOS DRONES EN LA LUCHA CONTRA EL TERRORISMO.-2.1. Creciente utilización de los drones.-2.2. Argumentos a favor de los drones.-2.3. Limitaciones de la utilización de los drones.-3. LOS DRONES ANTE EL DERECHO INTERNACIONAL.-3.1. Legalidad de los drones como arma de guerra.-3.2. Los ataques con drones ante el ius ad bellum.-3.2.1. La legítima defensa.-3.2.2. El consentimiento del Estado.-3.3. Los drones ante el ius in bello.-3.3.1. La existencia de un «conflicto armado».-3.3.2. Los principios de distinción, proporcionalidad, necesidad militar y humanidad.-3.4. Los drones ante el DIDH.-4. CONCLUSIONES.

\section{INTRODUCCIÓN}

Los atentados terroristas del 11 de septiembre de 2001 en Estados Unidos y la respuesta por parte del gobierno norteamericano y de alguno de sus aliados han venido a poner en cuestión el alcance y la aplicación de algunas categorías básicas tanto del Derecho internacional público en general como del Derecho internacional humanitario (DIH) y del Derecho internacional de los derechos humanos (DIDH) en particular ${ }^{1}$. La proclamación por parte de

* La investigación en la que se basa este artículo se ha desarrollado gracias a una estancia de investigación en Fordham Law School (Nueva York) entre agosto y septiembre de 2013. Agradezco a Joana Abrisketa y a María Luisa Sánchez Barrueco por los oportunos comentarios sobre una versión anterior de este artículo.

1 BhutA, N., "States of Exception: Regulating Targeted Killing in a "Global Civil War"», en Alston, P. y MacDonald, E. (eds.), Human Rights, Intervention and the Use of Force, Oxford, Oxford University Press, 2008, p. 245. Véase también CASSESE, A., «Terrorism is Also Disrupting Some Crucial 
la Administración de George W. Bush de que nos encontramos en un escenario de "guerra contra el terrorismo» ${ }^{2}$ (war on terror) ha hecho tambalearse alguno de los cimientos del Derecho internacional contemporáneo trabajosamente construidos desde 1945. Desde la creación del centro de detención de Guantánamo hasta la utilización sistemática de la tortura como forma de interrogar a presuntos terroristas, pasando por el empleo de asesinatos selectivos como medio para interceptar a militantes de la red terrorista Al-Qaeda, lo cierto es que todas estas prácticas suscitan serias dudas tanto desde el punto de vista jurídico como desde un plano estrictamente ético. Es en este contexto de lucha contra el terrorismo donde se enmarca la creciente utilización de aparatos aéreos no tripulados ${ }^{3}$, conocidos popularmente como dro$n e s^{4}$, tanto para labores de vigilancia como para la eliminación de terroristas de Al-Qaeda. Debemos reconocer que los drones se han convertido en un elemento estratégico clave dada la naturaleza asimétrica de la mayor parte de los conflictos contemporáneos y dadas las ventajas asociadas a su utilización. Todo ello apunta a que la extensión del uso de drones con fines militares es un proceso de carácter irreversible. Tal y como ha señalado el Relator Especial sobre ejecuciones extrajudiciales, sumarias o arbitrarias, Christof Heyns, «los drones están aquí para quedarse» ${ }^{5}$.

El presente artículo tiene por objeto analizar las principales cuestiones jurídico-internacionales planteadas por la utilización de los drones por parte de Estados Unidos en teatros de operaciones tan distintos como Afganistán, Irak, Pakistán, Yemen o Somalia. Mientras que la primera parte del artículo

Legal Categories of International Law», European Journal of International Law, vol. 12, 2001, núm. 5, pp. 993-1001.

2 Tan sólo tres días después de los atentados del 11 de septiembre, el Congreso y el Senado norteamericanos en sesión conjunta aprobaron la que se conoce como Authorization to Use Military Force (AUMF). En ella, sobre la base del derecho a la legítima defensa y a proteger a los ciudadanos de Estados Unidos tanto dentro del país como fuera, establecieron «that the President is authorized to use all necessary and appropriate force against those nations, organizations, or persons he determines planned, authorized, committed, or aided the terrorist attacks that occurred on September 11, 2001, or harbored such organizations or persons, in order to prevent any future acts of international terrorism against the United States by such nations, organizations or persons», S. J. Res. 23, September 14, 2001 (la redonda es nuestra). Donde quedan claramente delimitados los contornos de la guerra contra el terrorismo es en el documento estratégico elaborado por el gobierno norteamericano, National Strategy for Combating Terrorism, Washington D. C., February 2003.

3 La terminología utilizada es muy variada, pero básicamente podemos distinguir entre «unmanned aerial vehicles» (UAV), para aquellos aviones no tripulados que tienen como propósito básicamente labores de vigilancia y de obtención de información, y «unmanned combat aerial vehicles» (UCAV), para aquellos que pueden llevar misiles y, por tanto, ser utilizados en labores de combate. Véase al respecto Melzer, N., Implications of the Usage of Drones and Unmanned Robots in Warfare, Directorate-General for External Policies of the Union, European Union, Brussels, May 2013, p. 6. Sobre la creciente automatización de los métodos de guerra, véase SingeR, P. W., Wired for War: Robotics Revolution and Conflict in the $21^{\text {st }}$ Century, Nueva York, Penguin Press, 2009.

4 No se sabe a ciencia cierta de dónde proviene el término «drone», pero algunos apuntan a que su origen se encuentra en el zumbido («buzzing») constante de estos aparatos cuando están sobrevolando una determinada zona de manera continua, en Benjamin, M., Drone Warfare. Killing by Remote Control, Brooklyn, Verso, 2013, p. 13.

5 Heyns, C., Informe del Relator Especial sobre las ejecuciones extrajudiciales, sumarias o arbitrarias, Doc. ONU A/68/382, 13 de septiembre de 2013, p. 4. 
está destinada a describir los pros y los contras de la creciente utilización de drones en los conflictos armados contemporáneos, en la segunda abordamos los principales interrogantes de carácter jurídico-internacional. Así, analizamos la legalidad de los drones como arma de guerra per se, su legalidad desde el punto de vista del ius ad bellum y del ius in bello para, por último, entrar de lleno en su consideración desde la óptica del DIDH. Si bien los drones no constituyen un arma prohibida por el DIH debido a su carácter indiscriminado, su utilización en el marco de un conflicto armado se debe regir en todo momento por los principios de distinción, proporcionalidad, necesidad militar y humanidad. Lo cierto es que los datos que resultan de la práctica de la utilización de los drones nos hacen acercarnos a este artefacto bélico con notables precauciones. Si el uso de los drones se produce, en cambio, en una situación en la que no nos encontramos en un conflicto armado, las normas del DIDH hacen que sea prácticamente imposible su justificación legal.

\section{LOS DRONES EN LA LUCHA CONTRA EL TERRORISMO}

\subsection{Creciente utilización de los drones}

El uso de los aparatos aéreos no tripulados pilotados por control remoto no es un fenómeno nuevo en el marco de los conflictos armados. Existen antecedentes de utilización de drones con fines de vigilancia tanto durante la Primera como durante la Segunda Guerra Mundial, así como en la guerra de Corea. El paso de labores de vigilancia a tareas de combate llega con la guerra de Vietnam, las operaciones del ejército israelí en Líbano en 1982 y con las guerras de los Balcanes en los años noventa, en particular con las operaciones de la OTAN en Kosovo ${ }^{6}$. Ahora bien, la explosión en la utilización de drones equipados con armamento pesado ha venido de la mano de la lucha contra el terrorismo tras los atentados del 11 de septiembre.

Se calcula que actualmente más de setenta Estados cuentan con drones para ser utilizados en labores de vigilancia doméstica o en operaciones militares, o están desarrollando la tecnología apropiada para su construcción, e incluso hay evidencias de que algunos grupos armados de carácter no estatal también han accedido a este tipo de artefactos ${ }^{7}$. Estamos asistiendo, en opinión del Instituto Internacional de Estudios Estratégicos, a un claro ejemplo de proliferación a escala global de este tipo de tecnología ${ }^{8}$. Es por ello que

6 Gertler, J., «U.S. Unmanned Aerial Systems», Congressional Research Service Report for Congress, Washington D. C., 3 January, 2012, pp. 1-2.

7 En octubre de 2012 Hezbollah asumió el lanzamiento de un dron de reconocimiento y de combate Shahed-129 desarrollado por Irán. Este aparato aéreo fue derribado por Israel tras haberse adentrado 25 millas en su territorio y haber filmado el reactor nuclear de Dimona, en «Iran admits Hezbollah's drone over Israel used Iranian technology", Israel Hayom, Sunday 14 October, 2012, en http://www. israelhayom.com/site/newsletter_article.php?id=6075.

8 The Military Balance 2014, Londres, The International Institute for Strategic Studies, 2014, pp. 13-18. 
observamos una creciente atención al fenómeno de los drones tanto por parte de las fuerzas armadas como por parte de los Ministerios de Defensa y de Interior, así como por parte de la industria militar, la opinión pública y los medios de comunicación. La investigación y el desarrollo de estos aparatos pilotados por control remoto mueve un negocio en franca expansión, que ha pasado a formar parte de lo que el presidente Eisenhower denominó el "complejo militar-industrial», una alianza de intereses que se retroalimenta entre altos sectores del Ministerio de Defensa y de las fuerzas armadas y las grandes empresas del sector aeronáutico y del sector militar. Según estimaciones de la industria dedicada a la fabricación de los drones, entre 2011 y 2020 se invertirán solamente en Estados Unidos alrededor de 94 billones de dólares ${ }^{9}$. Hasta ahora, el liderazgo lo han llevado empresas norteamericanas e israelíes, pero hay otros países como China, Gran Bretaña ${ }^{10}$, Irán, Sudáfrica o Colombia que están promoviendo la inversión en un sector con un gran futuro económico ${ }^{11}$.

Como hemos puesto de manifiesto, la actual escalada en la utilización de los drones con fines militares se ha producido tras los atentados terroristas del 11 de septiembre de 2001 en Estados Unidos. El mantra de la «guerra contra el terrorismo" se ha convertido en el caldo de cultivo idóneo para la justificación de un uso cada vez más frecuente de los aparatos no tripulados para llevar a cabo asesinatos selectivos de militantes de la red terrorista AlQaeda. Fue la Administración Bush la que comenzó a utilizar asiduamente

9 Benjamin, M., op. cit., nota 4, p. 32.

10 En Europa, el 75 por 100 de la producción en este sector le corresponde a Gran Bretaña y a Francia, en 2013 Worldwide Roundup, Virginia, The American Institute of Aeronautics and Astronautics, 2013. Es por ello que países como España, que representa un escaso 6 por 100 del total de la producción europea, están tratando de hacerse un hueco en este floreciente mercado, como lo demuestra la celebración de un Congreso sobre el tema de los drones en Madrid en marzo de 2014 en el que se reunieron el sector de la industria relacionado con los drones y miembros de diferentes Ministerios de Defensa y de Interior de varios países, «El “dron” español vuela bajo», El País, 9 de marzo de 2014, p. 43.

11 Buena prueba de que los países de la Unión Europea (UE) no se quieren quedar atrás en este sector estratégico es que el Consejo Europeo decidió en diciembre de 2013 mejorar las capacidades en «el desarrollo de los sistemas de aeronaves pilotadas a distancia de gran autonomía y altitud media de la próxima generación», para lo que se habilitará «financiación adecuada de las actividades de I+D a partir de 2014», Consejo Europeo, "Conclusiones del Consejo Europeo (19 y 20 de diciembre de 2013)», EUCO 217/13, Bruselas, 20 de diciembre de 2013, p. 5. Es uno de los proyectos emblemáticos del impulso que la UE quiere dar a la política de defensa europea y a la industria militar para no depender como hasta ahora de la tecnología desarrollada en Estados Unidos, "Europa desarrollará sus "drones" para no depender de Estados Unidos», El Periódico, 20 de diciembre de 2013, en http://www.elperiodico. com/es/noticias/internacional/europa-desarrollara-sus-drones-para-depender-eeuu-2944194. En este contexto, siete Estados miembros (Francia, Alemania, Grecia, Italia, Holanda, Polonia y España) acaban de firmar una carta de intenciones con la Agencia Europea de Defensa (AED) para elaborar un estudio sobre la producción conjunta de drones de altitud media y gran autonomía. Esta posición de varios países miembros y del Consejo Europeo favorable al desarrollo de drones en territorio europeo contrasta con una resolución aprobada por el Parlamento Europeo el 27 de febrero de 2014 en la que expresa una postura bastante crítica con el componente militar del uso de los drones. En este sentido, el Parlamento Europeo «manifiesta su grave preocupación en relación con el empleo de drones armados fuera del marco jurídico internacional» e «insta a la UE a que desarrolle una respuesta política adecuada a nivel europeo y mundial que respete los derechos humanos y el Derecho humanitario internacional», 2014/2567(RSP). 
los drones en el marco de operaciones militares en Afganistán e Irak. En este contexto, la guerra contra el terrorismo se configura como un conflicto armado en el que no existen limitaciones ni espaciales ni temporales; nos encontramos ante una guerra sin fin contra los terroristas, se encuentren donde se encuentren, en la que rigen las reglas del DIH ${ }^{12}$. Contra todo pronóstico, ha sido bajo la Administración del presidente Barack Obama cuando se ha intensificado el programa de asesinatos selectivos con drones y se ha ampliado notablemente el ámbito geográfico donde se utilizan los citados aparatos bélicos para incluir países como Pakistán, Somalia o Yemen, donde no está tan claro que Estados Unidos se encuentre en una situación de conflicto armado con los grupos terroristas que operan en esos territorios. La Administración Obama trató de distanciarse desde la misma toma de posesión del presidente en enero de 2009 de la retórica de la "guerra contra el terrorismo» ${ }^{13}$. En palabras del propio Obama, «debemos definir nuestro esfuerzo no como una "guerra global contra el terrorismo" sin ningún tipo de límite, sino más bien como una serie de esfuerzos persistentes dirigidos a desmantelar redes de extremistas violentos que amenacen a América» ${ }^{14}$. Ahora bien, en el mismo discurso, en un pronunciamiento que parece contradecir su afirmación anterior, Obama señala que «Estados Unidos está en guerra con Al-Qaeda, los talibanes y fuerzas asociadas» ${ }^{15}$ (la cursiva es nuestra). Y finaliza su discurso con una referencia al elemento temporal de la lucha contra el terrorismo, señalando que «nuestro esfuerzo sistemático para desmantelar organizaciones terroristas debe continuar. Pero esta guerra, como todas las guerras, debe tener un final» ${ }^{16}$. Por tanto, a pesar de los proclamados intentos de alejarse de la doctrina de la "guerra contra el terrorismo», lo cierto es que este contradictorio discurso de Obama y, sobre todo, las prácticas desplegadas en la utilización de los drones en el marco de la lucha contra el terrorismo, revelan cambios más cosméticos y de retórica que transformaciones reales en las grandes líneas de la política antiterrorista. Como ha puesto de relieve Robert Barnidge a este respecto, «Guantánamo sigue abierto, Estados Unidos no ha ratificado el Estatuto de la Corte Penal Internacional, y muchas de las políticas contra el terrorismo

12 Sterio, M., «The United States' Use of Drones in the War on Terror: The (Il)legality of Targeted Killings Under International Law», Case Western Reserve Journal of International Law, vol. 45, 2012, pp. 201-202.

13 Ante las críticas vertidas desde determinados sectores en el sentido de que la política antiterrorista del Presidente Obama refleja una gran continuidad con la de su predecesor, Harold Hongju Koh, asesor jurídico del Departamento de Estado, ha manifestado que «la diferencia más importante es su enfoque y su actitud hacia el Derecho internacional». Lo que nos hace más fuertes y más seguros como nación es «respetar las normas tanto de Derecho interno como de Derecho internacional; cumplir con estándares de carácter universal, sin dobles raseros», KoH, H. H., "The Obama Administration and International Law», Speech to the Annual Meeting of the American Society of International Law, 25 March 2010, p. 3, en http://www.state.gov/s/l/releases/remarks/139119.htm.

14 Овама, B., "Remarks by the President at the National Defense University», National Defense University, Fort McNair, Washington, D. C. 23 May 2013, p. 4, en http://www.whitehouse.gov/the-pressoffice/2013/05/23/remarks-president-national-defense-university.

15 Ibid., p. 5.

16 Ibid., p. 10. 
de la Administración Bush siguen en pie, aunque sin utilizar el lenguaje de la "guerra contra el terrorismo" ${ }^{17}$.

En lo relativo al programa de drones bajo la Administración Obama, observamos una enorme escalada en el número de ataques selectivos desde que Obama asume la Presidencia ${ }^{18}$. Aunque no podemos contar con datos totalmente fiables, dado el secretismo que rodea todo lo relacionado con las operaciones militares con drones y dada la dificultad del acceso a la información en el terreno por cuestiones de seguridad, se calcula que los ataques selectivos con drones se han multiplicado por más de cinco desde $2009^{19}$. Asimismo, otra de las características del programa de drones bajo la Administración Obama es el incremento de los denominados «signature strikes» ${ }^{20}$, ataques basados en las características y en los patrones de comportamiento de las personas y grupos, y no en la demostrada identidad y en la participación de las personas que van a ser eliminadas en actividades terroristas («personality strikes»). Como veremos más adelante, estos ataques basados en presunciones de pertenencia a un grupo terrorista y de participación directa en las hostilidades basadas en patrones de comportamiento suscitan una seria preocupación desde la óptica de principios básicos del DIH como son los principios de distinción entre civiles y combatientes, de humanidad, de proporcionalidad y de precaución ${ }^{21}$, ya que amplían notablemente las personas que pueden convertirse en objetivos legítimos de un ataque con drones ${ }^{22}$.

\subsection{Argumentos a favor de los drones}

El principal argumento que utilizan los defensores de los drones como arma legítima en la lucha contra el terrorismo de Al-Qaeda es su extraordinaria efec-

17 Barnidge, R. P., «A Qualified Defense of American Drone Attacks in NorthWest Pakistan Under International Humanitarian Law», Boston University International Law Journal, vol. 30, 2012, p. 411.

18 SANGER, D. E., Confront and Conceal. Obama's Secret Wars and Surprising Use of American Power, Nueva York, Broadway Paperbacks, 2013, p. 243. Véase también MazzetTi, M., The Way of the Knife. The CIA, a Secret Army, and a War at the Ends of the Earth, Nueva York, Penguin Press, 2013.

${ }_{19}$ Los datos más fiables, dado que están basados en fuentes desplegadas en los teatros de operaciones donde se producen los ataques con drones, los proporciona la organización no gubernamental de periodistas basada en Londres The Bureau of Investigative Journalism. Según sus datos, solamente en el primer año de la Presidencia de Obama, 2009, se produjeron más ataques selectivos con drones en Pakistán (51) que en los cinco años anteriores de George Bush (2004-2008). 2010 fue el año con más ataques selectivos con drones (128), mientras que asistimos a un descenso paulatino desde 2011 (75), 2012 (50), hasta 2013 (27). Véase al respecto su programa de investigación "Covert Drone War», en http://www.thebureauinvestigates.com/category/projects/drones/. Hay otras fuentes a las que se puede acudir, subrayando que hay una elevada coincidencia en los datos generales del programa de drones de Estados Unidos. Véase The Long War Journal. A Project of the Foundation for the Defense of Democracies, en http://www.longwarjournal.org/.

20 International Human Rights and Conflict Resolution Clinic at Stanford LaW School and Global Justice Clinic at New York University School of Law, Living Under Drones: Death, Injury, and Trauma to Civilians from US Drone Practices in Pakistan, 2012, p. 12, en http:/llivingunderdrones.org/.

21 Amnesty International, "Will I Be Next?". US Drone Strikes in Pakistan», Londres, 2013 (ASA 33/013/2013), p. 28.

22 Human Rights Watch, Between a Drone and Al-Qaeda. The Civilian Cost of US Targeted Killings in Yemen, Nueva York, 2013, p. 86. 
tividad. Los aparatos aéreos pilotados por control remoto se han convertido en un medio extremadamente eficiente para eliminar terroristas que suponen una amenaza para Estados Unidos y, además, previenen la organización de futuros ataques contra intereses norteamericanos. De acuerdo con datos recogidos por la New America Foundation, desde que Obama se instala en la Casa Blanca se han eliminado con drones más de 3.000 militantes talibanes y de Al-Qaeda, entre los cuales se encontraban más de 50 destacados líderes de estos grupos, líderes que no se reemplazan fácilmente ${ }^{23}$. Además, lo hacen «con un costo relativamente pequeño, sin riesgo para tropas norteamericanas y con menos bajas civiles que las que otros medios alternativos hubieran ocasionado» ${ }^{24}$. Es fundamentalmente la ausencia de riesgos para pilotos y soldados norteamericanos, que no se tienen que desplegar sobre el terreno, la que explica la alta popularidad que continúan teniendo los drones entre la opinión pública norteamericana ${ }^{25}$.

La efectividad de los drones va acompañada de su enorme precisión en tareas de vigilancia durante largos períodos de tiempo a personas sospechosas de llevar a cabo acciones terroristas ${ }^{26}$, lo que redunda en beneficio de la garantía del principio de distinción entre combatientes y civiles ${ }^{27}$. Es más, esa precisión se extiende al ataque en sí, que se va a poder dirigir con una exactitud casi quirúrgica únicamente a las personas que son consideradas como objetivos legítimos, limitando al máximo los daños colaterales. Esta precisión quirúrgica contribuiría a un mayor respeto de otro de los principios esenciales del DIH, el principio de proporcionalidad entre los beneficios militares conseguidos por el ataque y los daños causados. Como afirma en este sentido Laurie Blank, los drones parecen estar «especialmente bien diseñados para el cumplimiento de estas obligaciones» ${ }^{28}$.

23 New America Foundation, Drone Wars Pakistan: Analysis, Washington, D. C., 2013, en http:// natsec.newamerica.net/drones/pakistan/analysis.

24 Byman, D., «Why Drones Work. The Case for Washington's Weapon of Choice», Foreign Affairs, July/August 2013, p. 32.

25 Según una encuesta llevada a cabo en octubre de 2013 por el Pew Research Center, un 61 por 100 de la opinión pública norteamericana aprueba los ataques selectivos con drones (este porcentaje solamente es superado por Israel, con un 64 por 100 de apoyo), mientras que tan sólo un 30 por 100 los desaprueba. La principal preocupación que genera el uso de los drones son los daños causados a la población civil. En cambio, a nivel global, la utilización de drones es un fenómeno crecientemente impopular, con tan sólo cuatro países (Israel, Estados Unidos, Kenya y Sudáfrica) en los que los partidarios de los drones superan a los detractores. Véase al respecto PeW Research Center, Report questions drone use, widely unpopular globally, but not in the U.S., Washington, D. C., October 23, 2013, en http://www.pewresearch.org/fact-tank/2013/10/23/report-questions-drone-use-widely-unpopularglobally-but-not-in-the-u-s/.

26 LEwIS, M. W., «Drones and the Boundaries of the Battlefield», Texas International Law Journal, vol. 47, Issue 2, 2012, p. 297. Como señala este autor, que tiene experiencia militar pilotando aviones F-14, la mayor ventaja que ofrecen los drones es la cada vez más larga duración del sobrevuelo, llegando a las treinta horas con el Predator B y a las veinte horas con el Predator C, es decir, más de diez veces la autonomía de vuelo de los aviones de combate tripulados. Haciéndonos eco de sus palabras, «esto convierte a los drones en un arma especialmente diseñada para labores de vigilancia y de ataque en operaciones antiterroristas».

${ }_{27}$ Kramer, C., «The Legality of Targeted Drone Attacks as US Policy», Santa Clara Journal of International Law, vol. 9, Issue 2, 2011, p. 381.

28 Blank, L. R., "After "Top Gun": How Drone Strikes Impact the Law of War», University of Pennsylvania Journal of International Law, vol. 33, 2012, p. 697. 


\subsection{Limitaciones de la utilización de los drones}

Si bien debemos reconocer que la tecnología ofrece avances muy relevantes para el desarrollo de las hostilidades en el marco de un conflicto armado, obviamente también hay algunas sombras que planean sobre el uso de los drones. En primer lugar, la decisión de llevar a cabo un ataque con un dron contra un determinado objetivo debe estar basada en información muy precisa y muy fiable recogida por los servicios de inteligencia. A pesar de que los avances tecnológicos, incluyendo la utilización de aparatos aéreos no tripulados, han mejorado sensiblemente las capacidades de los servicios de inteligencia para recabar información antes de realizar un ataque, debemos reconocer que siguen existiendo fallos y lagunas que nos exigen aproximarnos a esta cuestión con ciertas precauciones. De hecho, nos enfrentamos ante uno de los principales problemas detectados en el uso de los drones: la escasa fiabilidad de algunas de las fuentes de inteligencia ${ }^{29}$, sobre todo en contextos tan complejos y tan alejados de los patrones occidentales como los que se dan en Afganistán, Pakistán ${ }^{30}$, Yemen o Somalia, donde los yihadistas se entremezclan con la población civil como parte de su estrategia. Según un informe reciente de la Universidad de Columbia y del Center for Civilians in Conflict (CIVIC), la supuesta precisión milimétrica de los ataques con drones está muy condicionada por «fallos sistemáticos en la inteligencia sobre la que se basan dichos ataques, entre los que destacan las limitaciones técnicas de la propia video-vigilancia,... la comprensión cultural y la fiabilidad de los informantes locales y de los propios gobiernos con los que se coopera» ${ }^{31}$.

Otro aspecto que cuestiona la precisión de los drones es lo que técnicamente se conoce como «latencia», que se refiere a «la diferencia entre el mo-

29 International Human Rights and Conflict Resolution Clinic at Stanford LaW School and Global Justice Clinic at New York University School Of LaW, op. cit., nota 20, p. 37. Uno de los casos más dramáticos expuestos en este exhaustivo informe (pp. 57-62) acerca de la utilización de los drones en Waziristán del Norte, la zona fronteriza entre Pakistán y Afganistán, se produjo el 17 de marzo de 2011, cuando dos misiles lanzados desde un dron impactaron de lleno en un depósito de autobuses en el que se había convocado una Jirga, es decir, una reunión comunitaria convocada por los líderes locales (Maliks) para resolver una disputa acerca de una mina de cromita. Los Maliks incluso habían tomado la precaución de alertar al puesto local del Ejército acerca de la celebración de la Jirga. Según las fuentes consultadas por los investigadores que realizaron este informe, 42 personas fallecieron como consecuencia del ataque, la mayor parte de ellas civiles, y 14 resultaron heridas. Ninguno de los ancianos que acudió a la Jirga sobrevivió al ataque. Las autoridades norteamericanas siguen insistiendo en que todos los que fallecieron eran «insurgentes». En cambio, el Gobierno de Pakistán ofreció una compensación a las familias de las víctimas, lo que fue rechazado por la mayor parte de ellas. Éste es tan sólo uno de los ejemplos en los que la falta de fuentes de inteligencia totalmente fiables puede llegar a ocasionar errores fatales. Desgraciadamente, casos similares aparecen documentados en diversas fuentes: Amnesty InTERnATIONAL, op. cit, nota 21; HumAn Rights WATch, op. cit., nota 22.

30 Para un interesante intento de explorar la compleja pero rica realidad que se esconde en la frontera entre Afganistán y Pakistán, y que, «resulta opaca a las cámaras instaladas en drones que sobrevuelan a miles de metros por encima», véase BASHIR, S. y CREWS, R. D. (eds.), Under the Drones. Modern Lives in the Afghanistan-Pakistan Borderlands, Cambridge, Harvard University Press, 2012.

31 Columbia law School Human Rights Clinic and Center for Civilians in Conflict, The Civilian Impact of Drones: Unexamined Costs, Unanswered Questions, Nueva York, 2012, p. 2. 
vimiento en el terreno y la llegada de la imagen de video vía satélite al piloto del dron» ${ }^{32}$. Esta diferencia puede hacer que el ataque no sea tan preciso como supuestamente debería ser. Además, el radio de acción de la explosión de un misil Hellfire de los que se lanzan desde los drones puede llegar a los quince o veinte metros, lo que, junto a la metralla que se proyecta en cada explosión, puede hacer que las consecuencias del impacto se extiendan bastante más allá del objetivo inicialmente identificado ${ }^{33}$.

El impacto en la población civil de la utilización de los drones no se limita tan sólo a las personas que se ven directamente afectadas por las consecuencias físicas y socioeconómicas de un ataque, sino que la vida y la conducta de poblaciones enteras se van a ver muy condicionadas por el sobrevuelo constante de estos aparatos y el temor ante un ataque en cualquier momento. El sobrevuelo de los drones veinticuatro horas al día en determinadas zonas de Pakistán y los ataques previos en casas, vehículos o espacios públicos sin ningún tipo de advertencia previa, han generado una sensación de terror entre hombres, mujeres y niños, dando lugar a fenómenos de ansiedad y estrés post-traumático entre la población ${ }^{34}$. El temor ante un nuevo ataque con drones ha afectado hasta tal punto la sensación de seguridad que «ha acabado minando la voluntad de la población de participar en actividades sociales como reuniones comunitarias, funerales o el simple hecho de enviar a sus hijos al colegio» ${ }^{35}$.

Otro riesgo asociado a la creciente utilización de drones en la lucha contra el terrorismo es lo que se conoce como la «mentalidad Play-Station» ${ }^{36}$. Este fenómeno alude al riesgo de que el manejo de los drones para ataques selectivos se acabe convirtiendo en una especie de juego virtual ${ }^{37}$, con una clara disociación física entre una decisión con consecuencias fatales que se toma desde un lugar que se encuentra a miles de kilómetros de la realidad sobre el terreno. Ello tendría como consecuencia que la decisión de «eliminar» a una persona se convierte en una decisión mucho más sencilla y aséptica, dada la distancia tanto física como emocional entre el operador del dron a miles de kilómetros de distancia y el presunto terrorista que va a ser eliminado ${ }^{38}$. Algunos apuntan a que esta disociación tanto física como emocional pue-

\footnotetext{
32 International Human Rights and Conflict Resolution Clinic at Stanford Law School and Global Justice Clinic at New York University School of LaW, op. cit., nota 20, p. 9.

33 Benjamin, M., op. cit., nota 4, p. 27.

34 International Human Rights and Conflict Resolution Clinic at Stanford law School and Global Justice Clinic at New York University School of LaW, op. cit., nota 20, p. 55.

35 Ibid.

36 Alston, P., Report of the Special Rapporteur on extrajudicial, summary or arbitrary executions. Study on Targeted Killings, Doc. ONU A/HRC/14/24/Add.6, 28 May 2010, p. 24.

37 Véase al respecto la interesante reflexión acerca de cómo los videojuegos afectan a las percepciones de sus usuarios en torno a lo que se puede y no se puede hacer en un conflicto armado y cómo los videojuegos se podrían convertir en una herramienta muy útil para ampliar el conocimiento de las normas del DIH y modificar la actitud hacia ellas, Clarke, B., Rouffaer, C. y SÉnéchaud, F., «Beyond the Call of Duty: why shouldn't video game players face the same dilemmas as real soldiers?», International Review of the Red Cross, vol. 94, 2012, núm. 886, pp. 711-737.

38 Sterio, M., op. cit., nota 12, p. 213.
} 
de conducir a una cierta des-sensibilización y a una «mayor propensión a matar» ${ }^{39}$. En cambio, desde otros ángulos se señala que este supuesto efecto psicológico de la mentalidad Play-Station no deja de ser un mito que no ha sido contrastado científicamente ${ }^{40}$. Al contrario, la distancia física, la calma, la ausencia de estrés y de cualquier tipo de peligro con la que se toman las decisiones en una sala con aire acondicionado a miles de kilómetros del campo de batalla pueden permitir decisiones mucho más racionales y consistentes con los principios básicos del DIH y del DIDH, que cuando esas decisiones se toman desde un avión de combate ${ }^{41}$.

Consideraciones estratégicas también pueden estar en la base del cuestionamiento del uso sistemático de los drones en operaciones antiterroristas. El propio John O. Brennan, asesor del presidente de Estados Unidos en asuntos de seguridad y política antiterrorista, ha manifestado que, a la hora de tomar la decisión de eliminar a un terrorista mediante un ataque con drones, se tienen en cuenta las «implicaciones estratégicas de cada acción» ${ }^{42}$. A pesar de este claro pronunciamiento, algunos ponen de relieve que «el problema para Washington es que el programa de drones ha cobrado vida propia, hasta tal punto que la táctica acaba dominando a la estrategia» ${ }^{43}$. La principal crítica vertida al programa de drones de Estados Unidos es que los ataques selectivos y el sobrevuelo constante de estos aparatos pilotados por control remoto no gozan de apoyo popular en los países en los que se utilizan, lo que puede contribuir a dañar las relaciones estratégicas con esos países que son clave en la lucha contra el terrorismo, como ha ocurrido claramente en el caso de Pakistán. En última instancia, los drones «fomentan sentimientos anti-americanos y acaban minando la credibilidad de Estados Unidos no sólo en Pakistán sino en toda la región» ${ }^{44}$. La encuesta ya citada del Pew Research Center sobre la opinión acerca del uso de los drones revela que Pakistán cuenta con uno de los niveles de apoyo popular más bajo, con un escaso 5 por 100 (solamente superado en falta de apoyo por Jordania y Palestina) ${ }^{45}$. Este desencuentro entre la población a la que supuestamente se va a ayudar y la política de uso de drones por parte de Estados Unidos puede acabar teniendo

39 Anderson, D. E., "Drones and the Ethics of War», Religion \& Ethics News Weekly, 14 May 2010, en http://www.pbs.org/wnet/religionandethics/2010/05/14/drones-and-the-ethics-of-war/6290/.

40 Advisory Committee on Issues of Public International LaW, Main Conclusions of Advice on Armed Drones, La Haya, July 2013, p. 1. Además, como subraya este informe del Comité Asesor sobre Cuestiones de Derecho internacional del Gobierno holandés, aunque se demostrara la existencia de este fenómeno Play-Station, la cuestión de su relevancia jurídica sigue siendo "poco clara».

41 McCloskey, M., «The War Room: Daily Transition between Battle, Home Takes a Toll on Drone Operators», Stars and Stripes, 27 October 2009, en http://www.stripes.com/news/the-war-room-dailytransition-between-battle-home-takes-a-toll-on-drone-operators-1.95949.

42 Brennan, J. O., "The Ethics and Efficacy of the President's Counterterrorism Strategy», Address at the Woodrow Wilson Center for Scholars, 30 April 2012, p. 11, en http://www.wilsoncenter.org/event/ the-efficacy-and-ethics-us-counterterrorism-strategy.

${ }^{43}$ Cronin, A. K., "Why Drones Fail. When Tactics Drive Strategy», Foreign Affairs, July/August 2013 , p. 44.

44 International Human Rights and Conflict Resolution Clinic at Stanford Law School and Global Justice Clinic at New York University School of LaW, op. cit., nota 20, p. 125.

45 Pew Research CEnTER, op. cit., nota 25. 
el efecto contraproducente de fomentar actitudes de revancha y de simpatía hacia los grupos terroristas ${ }^{46}$. Como se ha señalado a este respecto, «los drones han reemplazado a Guantánamo como herramienta de reclutamiento de nuevos terroristas» ${ }^{47}$.

Por último, el programa de drones también suscita dudas al poder convertirse en un peligroso precedente tanto para otros países como para actores no estatales que quieran seguir la senda iniciada por Estados Unidos e Israel, abriendo una caja de Pandora de imprevisibles consecuencias ${ }^{48}$. La creciente percepción de los drones como una estrategia exitosa en la lucha contra el terrorismo puede hacer que se conviertan en «la norma y desplacen otras alternativas que podrían ser mucho más respetuosas con la población civil» ${ }^{49}$. El mismo Obama es consciente del poder que tienen los drones para sentar un precedente cuando admite que su uso «definirá el tipo de nación (y de mundo) que dejamos a nuestros hijos» ${ }^{50}$.

\section{LOS DRONES ANTE EL DERECHO INTERNACIONAL}

\subsection{Legalidad de los drones como arma de guerra}

Una de las reglas fundamentales que regulan los métodos de guerra en el marco del DIH es que dichos medios tienen límites ${ }^{51}$. Como dispone al

\footnotetext{
46 La siguiente cita es extremadamente reveladora de los efectos contraproducentes que puede acabar teniendo la estrategia de los drones en la lucha contra el terrorismo: «Los drones están haciendo que cada vez más yemeníes odien a Estados Unidos y se unan a los militantes radicales; no se mueven por ideología sino por sentimientos de venganza y desesperación... Más que ganar los corazones y las mentes de los civiles yemeníes, Estados Unidos los aliena cuando mata a sus parientes y amigos. De hecho, el programa de drones está conduciendo a la talibanización de vastas áreas tribales y a la radicalización de gente que bien podría ser aliada de Estados Unidos en la lucha contra el terrorismo en Yemen», Mothana, I., "How Drones Help Al Qaeda», New York Times, 13 June 2013, en http://www. nytimes.com/2012/06/14/opinion/how-drones-help-al-qaeda.html.

47 Becker, J. y Shane, S., "Secret "Kill List" Proves a Test of Obama's Principles and Will», New York Times, 29 May 2012, en http://www.nytimes.com/2012/05/29/world/obamas-leadership-in-war-on-alqaeda.html? pagewanted $=$ all\&_r=0.

48 CASEY-Maslen, S., "Pandora's box? Drone strikes under jus ad bellum, jus in bello, and international human rights law», International Review of the Red Cross, vol. 94, 2012, núm. 886, pp. 624-625. Por citar tan sólo un ejemplo mencionado con ciertas dosis de preocupación por el Relator Especial Philip Alston, en 2006 el Parlamento ruso aprobó una ley que permite a los servicios secretos rusos asesinar selectivamente a supuestos terroristas fuera de Rusia con la autorización del presidente, Federal Law núm. 35-FZ on Counteracting Terrorism, en http://www.coe.int/t/dlapil/codexter/Source/country_profiles/legislation/CT\%20legislation\%20-\%20Russian\%20Federation.pdf. El problema con esta ley, como señala el Relator, es que «no hay ningún tipo de información pública acerca de salvaguardas procedimentales para asegurar que los asesinatos selectivos sean legales, los criterios para decidir quién puede ser un objetivo legítimo o mecanismos de rendición de cuentas y de revisión de las operaciones de asesinatos selectivos», Alston, P., op. cit., nota 36, p. 9.

49 Columbia law School Human Rights Clinic and Center for Civilians in Conflict, op. cit., nota 31, p. 3.

50 Овама, B., op. cit., nota 14, p. 2.

51 Véase un análisis general en Boотнвy, W., Weapons and the Law of Armed Conflict, Oxford, Oxford University Press, 2009.
} 
respecto el art. 35.1 del Protocolo I Adicional a los Convenios de Ginebra de 1949 relativo a la protección de las víctimas de los conflictos armados internacionales ${ }^{52}$, «en todo conflicto armado, el derecho de las Partes en conflicto a elegir los métodos o medios de hacer la guerra no es ilimitado» (la cursiva es nuestra) ${ }^{53}$. Uno de los límites se concreta en la prohibición de aquellas armas y métodos de hacer la guerra «que causen males superfluos o sufrimientos innecesarios» ${ }^{54}$. El otro límite se refiere a la prohibición de las armas cuyo uso tiene un carácter indiscriminado, es decir, no tienen capacidad para «dirigirse contra un objetivo militar concreto» ${ }^{55} \mathrm{O}$ "cuyos efectos no sea posible limitar conforme a lo exigido por el presente Protocolo» ${ }^{56}$. Estas normas, según Yoram Dinstein ${ }^{57}$, habrían adquirido el carácter de Derecho internacional consuetudinario, obligando, por tanto, a todos los actores que intervienen en un conflicto armado.

Una de las consecuencias más relevantes de estas limitaciones a las armas y a los métodos de guerra es que cuando se está desarrollando un arma nueva, los Estados tienen que llevar a cabo un estudio en profundidad sobre su compatibilidad con las limitaciones que acabamos de mencionar ${ }^{58}$. Éste es el sentido del art. 36 del Protocolo I Adicional que venimos comentando cuando establece que

«cuando una Alta Parte contratante estudie, desarrolle, adquiera o adopte una nueva arma, o nuevos medios o métodos de guerra, tendrá la obligación de determinar si su empleo, en ciertas condiciones o en todas las circunstancias, esta-

52 Adoptado el 8 de junio de 1977, entró en vigor el 7 de diciembre de 1978. A 10 de marzo de 2014 cuenta con 173 Estados parte.

${ }^{53}$ La Corte Internacional de Justicia se ha referido a esta norma como uno de los «principios cardinales» del Derecho humanitario. Para la Corte, «los Estados no tienen una libertad de elección ilimitada en cuanto a los medios y armas que utilizan", Legality of the Threat or Use of Nuclear Weapons, Advisory Opinion, ICJ Reports 1996, p. 257, párr. 78.

54 Art. 35.2 del Protocolo I Adicional a los Convenios de Ginebra de 1949. Al respecto, la Corte Internacional de Justicia ha reiterado que «está prohibido causar sufrimiento innecesario a los combatientes: por tanto, está prohibido el uso de armas que causen dicho sufrimiento o que agraven inútilmente su sufrimiento", Legality of the Threat or Use of Nuclear Weapons, op. cit., nota 53, p. 257, párr. 78 .

55 Ibid., art. 51.4.b). La Corte Internacional de Justicia también se ha referido a que «los Estados nunca deben convertir a los civiles en objeto de un ataque y, en consecuencia, nunca deben usar armas que sean incapaces de distinguir entre objetivos civiles y objetivos militares", Legality of the Threat or Use of Nuclear Weapons, op. cit., nota 53, p. 257, párr. 78.

56 Ibid., art. 51.4.c).

57 Dinstein, Y., The Conduct of Hostilities under the Law of International Armed Conflict, 2. ${ }^{\mathrm{a}}$ ed., Cambridge, Cambridge University Press, 2010, p. 126.

58 Véase al respecto McClelland, J., «The review of weapons in accordance with Article 36 of Additional Protocol I», International Review of the Red Cross, vol. 85, 2003, núm. 850, pp. 397-415. El propio Comité Internacional de la Cruz Roja ha elaborado una Guía para llevar a cabo el proceso de revisión de las nuevas armas, International Committee of the ReD Cross, «A Guide to the Legal Review of New Weapons, Means and Methods of Warfare: Measures to Implement Article 36 of Additional Protocol I of 1977», International Review of the Red Cross, vol. 88, 2006, núm. 864, pp. 931-956. Ahora bien, de manera un tanto sorprendente, el Comité Internacional de la Cruz Roja no ha considerado que el art. 36 del Protocolo I Adicional a los Convenios de Ginebra haya pasado a formar parte del Derecho consuetudinario, Henckaerts, J.-M. y Doswald-Beck, L., Customary International Humanitarian Law, Cambridge, ICRC and Cambridge University Press, 2005. 
ría prohibido por el presente Protocolo o por cualquier otra norma de Derecho internacional aplicable a esa Alta Parte contratante» ${ }^{59}$.

La verdad es que, como concluyen la mayor parte de los autores que han analizado esta cuestión, dadas las capacidades técnicas de los drones y sus posibilidades en cuanto a la vigilancia constante de un determinado objetivo militar, no podemos considerar que per se constituyan un método de guerra indiscriminado que esté prohibido por el $\mathrm{DIH}^{60}$. Al contrario, si se utilizan adecuadamente, los drones se pueden convertir en armas que pueden discriminar con un alto grado de precisión entre objetivos militares y población civil y, en consecuencia, pueden minimizar en gran medida los daños colaterales $^{61}$. Ahora bien, esta afirmación es adecuada cuando los drones se utilizan en el marco de un conflicto armado regulado por el DIH. En cambio, cuando no nos encontramos en un escenario de conflicto armado, cuando el marco

59 A pesar de esta norma, «los más de setenta Estados que poseen drones no han hecho públicos sus análisis — si es que los han llevado a cabo- acerca de la legalidad de los drones armados», CASEYMASLEN, S., op. cit., nota 48, p. 601.

60 Pozo Serrano, P., «La utilización de los drones en los conflictos actuales: una perspectiva del Derecho internacional», Instituto Español de Estudios Estratégicos, Documento de Opinión 37/2011, p. 7. Melzer, N., op. cit., nota 3, p. 27; Heyns, C., op. cit., nota 5, p. 4; Advisory Committee on Issues of Public International LaW, op. cit., nota 40, p. 1; Sterio, M., op. cit., nota 12, p. 209. La verdad es que sería difícil llegar a una solución diferente cuando la propia Corte Internacional de Justicia no ha podido llegar a una conclusión definitiva respecto de la ilegalidad de las armas nucleares. Como señaló la Corte en su polémica Opinión Consultiva de 1996, "there is in neither customary nor conventional international law any comprehensive and universal prohibition of the threat or use of nuclear weapons as such». La Corte prosigue su razonamiento subrayando que "the threat or use of nuclear weapons would generally be contrary to the rules o international law applicable in armed conflict, and in particular the principles and rules of humanitarian law». Finalmente, la Corte se ve obligada a concluir, en una votación muy ajustada (siete contra siete, con el voto de calidad del presidente) que «however, in view of the current state of international law, and of the elements of fact at its disposal, the Court cannot conclude definitively whether the threat or use of nuclear weapons would be lawful or unlawful in an extreme circumstance of self-defence, in which the very survival of a State would be at stake», Legality of the Threat or Use of Nuclear Weapons, op. cit., nota 53, p. 266.

61 BLANK, L. R., op. cit., nota 28, p. 687. Un aspecto que sí es problemático desde el punto de vista de la prohibición de los métodos de guerra indiscriminados tiene que ver con el desarrollo de una nueva fase en la creación de drones cada vez más autónomos que permitirían tomar decisiones programadas acerca de objetivos militares legítimos sin intervención humana. Según Nils Melzer, hoy por hoy la utilización legítima de la fuerza mediante drones «siempre requiere de la implicación directa de un controlador humano», MELzer, N., op. cit., nota 3, p. 11. Una opinión muy similar es compartida por Peter Asaro cuando afirma que desde un punto de vista moral y desde un punto de vista jurídico "no podemos aceptar que un sistema totalmente automatizado tome decisiones relativas a la privación de la vida humana», ASARo, P., «On banning autonomous weapon systems: human rights, automation, and the dehumanization of lethal decision-making», International Review of the Red Cross, vol. 94, 2012, núm. 886, p. 708. Véase en el mismo sentido Gutiérrez EspadA, C. y Cervell Hortal, M. J., "Sistemas de Armas Autónomas, Drones y Derecho internacional», Revista del Instituto Español de Estudios Estratégicos, 2013, núm. 2, pp. 27-57. Ahora bien, como señalan estos autores, «en el estado actual de su desarrollo científico y tecnológico, tampoco puede excluirse a priori la posibilidad de que pueda introducirse en el futuro en sus programas informáticos un "regulador ético" que elimine o minimice muy significativamente la eventualidad de una conducta contraria a los mencionados principios» del DIH y del DIDH (op. cit., p. 51). Pero debemos estar alerta, ya que la investigación y el desarrollo en este campo caminan hacia la creación de sistemas con un grado de autonomía operativa cada vez mayor. Véase en este sentido BACKSTROM, A. y Henderson, I., "New capabilities in warfare: an overview of contemporary technological developments and the associated legal and engineering issues in Article 36 weapons reviews», International Review of the Red Cross, vol. 94, 2012, núm. 886, pp. 483-514. 
legal aplicable es el del DIDH, la justificación de los drones resulta mucho más problemática, como vamos a ver más adelante.

\subsection{Los ataques con drones ante el ius ad bellum}

Un primer aspecto que tenemos que abordar es la caracterización jurídica de la respuesta armada, incluyendo el uso de drones, por parte de un Estado ante un ataque terrorista, sobre todo tras los ataques del 11 de septiembre de 2001 y la emergencia del terrorismo como un fenómeno de alcance global.

Como sabemos, uno de los principios estructurales del Derecho internacional contemporáneo se refiere a la prohibición del uso de la fuerza en las relaciones internacionales ${ }^{62}$, principio que se ha convertido en una norma de naturaleza consuetudinaria ${ }^{63}$. El art. 2.4 de la Carta de las Naciones Unidas establece que «los Miembros de la Organización, en sus relaciones internacionales, se abstendrán de recurrir a la amenaza o al uso de la fuerza contra la integridad territorial o la independencia política de cualquier Estado...». Solamente hay tres excepciones a este principio: el consentimiento del Estado en el que tiene lugar la respuesta armada, la legítima defensa y la autorización del uso de la fuerza por parte del Consejo de Seguridad de las Naciones Unidas. Si no nos encontramos ante ninguna de estas excepciones, un ataque armado constituiría un acto de agresión prohibido por el Derecho internacional. Así fue considerado por el Consejo de Seguridad de las Naciones Unidas el asesinato selectivo de Khalil Al-Wazir, más conocido como Abu Yihad, por parte de los servicios secretos de Israel en Túnez el 16 de abril de $1988^{64}$.

La tercera excepción a la que nos hemos referido relativa a la autorización por parte del Consejo de Seguridad es inaplicable en la mayor parte de los escenarios en los que se utilizan los drones, ya que la única operación militar que cuenta con el aval del máximo órgano de las Naciones Unidas en materia de paz y seguridad es la que ha tenido lugar en Afganistán ${ }^{65}$. Por tanto, sola-

62 Márouez Carrasco, M. C., Problemas actuales sobre la prohibición del recurso a la fuerza en Derecho internacional, Madrid, Tecnos, 1998. Véase también GRAY, C., International Law and the Use of Force, Oxford, Oxford University Press, 2001; Gutiérrez EsPada, C. y Cervell Hortal, M. J., El Derecho internacional en la encrucijada. Curso General de Derecho Internacional Público, Madrid, Trotta, pp. 395 y ss.

${ }^{63}$ Military and Paramilitary Activities in and against Nicaragua (Nicaragua v. United States of America), Merits, Judgment, ICJ Reports 1986, p. 98, párr. 185.

${ }_{64}$ Abu Yihad era co-fundador y comandante militar de Fatah. El Consejo de Seguridad condenó «enérgicamente la agresión perpetrada... contra la soberanía y la integridad territorial de Túnez en patente violación de la Carta de las Naciones Unidas, del Derecho y de las normas de conducta internacionales», Resolución 611 (1988), de 25 de abril. Esta resolución contó con 14 votos favorables, ninguno en contra y la abstención de Estados Unidos. Para los detalles de esta operación véase BLACK, I. y MorRIs, B., Israel's Secret Wars: A History of Israel's Intelligence Services, Nueva York, Grove Weidenfeld, 1991.

65 Un día después de los atentados terroristas del 11 de septiembre en Nueva York, Washington, D. C. y Pennsylvania, el Consejo de Seguridad aprobó la Resolución 1368 (2001), de 12 de septiembre, en la que, además de reafirmar «el derecho inmanente de legítima defensa individual o colectiva de conformidad con la Carta de las Naciones Unidas», considera que dichos atentados «constituyen una 
mente nos quedan las otras dos excepciones para poder explorar la justificación del uso de drones en la lucha contra el terrorismo.

\subsubsection{La legítima defensa}

Una de las excepciones más relevantes al principio de la prohibición del uso de la fuerza en las relaciones internacionales es la legítima defensa ${ }^{66}$. Como establece la Carta de las Naciones Unidas en su art. 51:

«Ninguna disposición de esta Carta menoscabará el derecho inmanente de legítima defensa, individual o colectiva, en caso de ataque armado contra un Miembro de las Naciones Unidas, hasta tanto que el Consejo de Seguridad haya tomado las medidas necesarias para mantener la paz y la seguridad internacionales...».

El principal argumento al que alude Estados Unidos para justificar la utilización de drones en la lucha contra el terrorismo es su derecho a la legítima defensa ante ataques que constituyen una amenaza y ponen en peligro su seguridad ${ }^{67}$. Uno de los pronunciamientos más claros a este respecto ha venido de la mano de la Asesoría Jurídica del Departamento de Estado cuando afirma que «desde el punto de vista del Derecho internacional, Estados Unidos está en una situación de conflicto armado con Al-Qaeda, así como con los talibanes y fuerzas asociadas, en respuesta a los terribles atentados del 11 de septiembre, por lo que puede recurrir al uso de la fuerza basándose en su derecho inmanente a la legítima defensa» ${ }^{68}$.

Un primer aspecto que hay que analizar es la naturaleza y el alcance de los ataques, es decir, si se puede considerar que dichos ataques han cruzado el umbral exigido para ser calificados como un «ataque armado», tal y como exige la Carta de las Naciones Unidas, que abra las puertas a la legítima defensa. Como observó la Corte Internacional de Justicia en el Caso de las Actividades Militares y Paramilitares en y contra Nicaragua, es necesario distinguir «las formas más graves de uso de la fuerza (aquellas que constituyen un

amenaza para la paz y la seguridad internacionales». A finales de septiembre, el Consejo aprobó la Resolución 1373 (2001), de 28 de septiembre, en la que estableció toda una batería de medidas para luchar contra el terrorismo. Por su parte, el Consejo expresó su determinación de adoptar «todas las medidas necesarias para asegurar la plena aplicación de la presente resolución» (la cursiva es nuestra). Ésta fue la base jurídica sobre la que Estados Unidos inició la intervención militar en Afganistán.

${ }^{66}$ En opinión de la Corte Internacional de Justicia, el derecho de legítima defensa también se ha convertido en una norma de carácter consuetudinario, Military and Paramilitary Activities in and against Nicaragua..., op. cit., nota 63, p. 103, párr. 194.

67 La Authorization to Use Military Force (AUMF) aprobada por el Congreso y el Senado norteamericanos el 14 de septiembre de 2001 establece que los atentados del 11 de septiembre «hacen necesario y apropiado que Estados Unidos ejerza su derecho de legítima defensa», op. cit., nota 2.

${ }_{68} \mathrm{KoH}, \mathrm{H}$. H., op. cit., nota 13, p. 13. Véase en el mismo sentido la postura del asesor del presidente en asuntos de seguridad y política antiterrorista, BrennAN, J. O., op. cit., nota 42, p. 7. El Presidente Obama se ha referido a que esta guerra contra Al-Qaeda, los talibanes y sus fuerzas asociadas, es una guerra «justa», guiada por el principio de "proporcionalidad», como "último recurso» y «en legítima defensa», Овама, B., op. cit., nota 14, p. 5. 
ataque armado) de otras formas menos graves» ${ }^{69}$. Hay algunos que defienden que los ataques de Al-Qaeda, incluso teniendo en cuenta el conjunto de todos los ataques lanzados por esta red terrorista desde principios de los años noventa, no constituyen una ofensiva militar a gran escala, lo que no daría lugar al ejercicio del derecho a la legítima defensa por parte de Estados Uni$\operatorname{dos}^{70}$. Sin embargo, ésta no es la postura mayoritaria ni entre la doctrina ${ }^{71}$ ni entre los Estados. Lo cierto es que, como señala Oriol Casanovas, con las Resoluciones 1368 (2001) y 1373 (2001) del Consejo de Seguridad "parece que la comunidad internacional quiso ampliar la noción de legítima defensa y considerar los ataques terroristas como susceptibles de enmarcarse en el concepto de "ataque armado" del art. 51 de la Carta» ${ }^{72}$. Ahora bien, esta afirmación puede servir en relación con los atentados del 11 de septiembre $\mathrm{u}$ otros ataques llevados a cabo por ciertos grupos terroristas desde la zona fronteriza de Pakistán con Afganistán contra intereses norteamericanos. Sin embargo, es mucho más difícil que las acciones terroristas del tipo de las que están aconteciendo en Somalia o en Yemen alcancen la intensidad y la gravedad necesarias como para constituir un ataque armado en el sentido del art. 51 de la Carta de las Naciones Unidas. Como ha señalado Philip Alston al respecto, «sólo en muy contadas ocasiones un actor no estatal que no esté vinculado con algún Estado estará en disposición de llevar a cabo el tipo de ataques armados que darían lugar al derecho a utilizar la fuerza con carácter extraterritorial» ${ }^{73}$.

Otro elemento que ha suscitado una notable controversia tiene que ver con el actor del ataque armado que puede dar lugar a la legítima defensa. La interpretación tradicional establece que solamente los ataques armados llevados a cabo por Estados pueden servir de base para poner en marcha la legítima defensa. Esta postura ha sido avalada en gran parte por la Corte Interna-

69 Op. cit., nota 63, p. 101, párr. 191. Véase sobre esta cuestión RuYs, T., «Armed Attack» and Article 51 of the UN Charter. Evolutions in Customary Law and Practice, Cambridge, Cambridge University Press, 2010.

${ }^{70}$ Sнан, S. A., "War on Terrorism: Self-Defense, Operation Enduring Freedom, and the Legality of U.S. Drone Attacks in Pakistan», Washington University Global Studies Law Review, vol. 9, 2010, núm. 1, p. 119. Una postura más matizada es la expresada por Pons Rafols y Paniagua, quienes sostienen que «hay dudas, incluso en el contexto de las resoluciones del Consejo de Seguridad, sobre la identificación de los actos de terrorismo del 11 de septiembre con un ataque armado que justifique el ejercicio de la legítima defensa», Pons RAFols, X. y PANiagua REDOndo, R., "El sistema de seguridad colectiva, el terrorismo internacional y la legítima defensa», Agenda $O N U, 2001$, núm. 4, p. 41. Véase en la misma línea ABRISKETA, J., «El Derecho internacional como alternativa a la fuerza armada», en $D e$ Nueva York a Kabul. Anuario CIP 2002, p. 56.

71 Dinstein, Y., War, Aggression, and Self-Defense, Cambridge, Cambridge University Press, 2005, p. 237; OrR, A. C., «Unmanned, Unprecedented, and Unresolved: The Status of American Drone Strikes in Pakistan Under International Law», Cornell International Law Journal, vol. 44, 2011, p. 737; ConDoRELLI, L., "Les attentats du 11 septembre et leurs suites: Ou va le droit international?», Revue Générale de Droit International Public, t. 105, 2001, núm. 4, p. 843; BARnIDGe, R. P., op. cit., nota 17, p. 428; BHuta, N., op. cit., nota 1, p. 262.

72 Casanovas y la Rosa, O., "El principio de la prohibición del uso de la fuerza tras el conflicto de Irak de 2003», en García Segura, C. y Rodrigo Hernández, A. J. (eds.), El Imperio Inviable. El orden internacional tras el conflicto de Irak, Madrid, Tecnos, 2004, p. 133.

73 Alston, P., op. cit., nota 36, p. 13. 
cional de Justicia. Como puso de manifiesto la Corte en la Opinión Consultiva relativa a la Construcción de un Muro en los Territorios Palestinos Ocupados, «el art. 51 de la Carta reconoce la existencia de un derecho inmanente de legítima defensa en el caso de un ataque armado de un Estado contra otro Estado» ${ }^{74}$ (la cursiva es nuestra). Ahora bien, en ese mismo párrafo, la Corte deja abierta la puerta abierta a una interpretación diferente, ya que dice que «la situación es distinta a la contemplada por las Resoluciones 1368 (2001) y 1373 (2001) del Consejo de Seguridad y, por tanto, Israel no podría invocar estas resoluciones para apoyar su pretensión de estar ejercitando su derecho de legítima defensa» ${ }^{75}$. Parece que, a sensu contrario, si la situación fuera similar, Israel sí podría invocar las citadas resoluciones que, como ya sabemos, fueron aprobadas tras los ataques terroristas del 11 de septiembre, ataques cometidos por un actor no estatal como Al-Qaeda. Es esta matización de la Corte la que le permite al juez Kooijmans señalar, en una opinión separada, que nos encontramos ante «una nueva aproximación al concepto de legítima defensa» ${ }^{76}$, postura compartida por la juez Rosalyn Higgins. Para la juez británica, «con todo el respeto, no hay nada en el texto del art. 51 que estipule que la legítima defensa solamente opera cuando el ataque armado sea cometido por un Estado» ${ }^{77}$. En un asunto contencioso dirimido un año más tarde, en 2005, la Corte perdió la oportunidad de haber dado un paso más y haber clarificado su postura expresada en la Opinión Consultiva que acabamos de analizar $^{78}$. Dado que las circunstancias tanto jurídicas como fácticas para el ejercicio de la legítima defensa por Uganda contra la República Democrática del Congo no estaban presentes, ya que los ataques contra Uganda no provinieron de las fuerzas armadas congoleñas sino de las denominadas Allied Democratic Forces (ADF), la Corte no vio «la necesidad de responder a los

${ }^{74}$ Legal Consequences of the Construction of a Wall in the Occupied Palestinian Territory, Advisory Opinion, ICJ Reports 2004, p. 194, párr. 139.

75 Ibid.

$76 \mathrm{Ibid}$., Separate Opinion of Judge Kooijmans, p. 230, párr. 36. Para un apoyo a esta postura véase CASEY-MASLEN, S., op. cit., nota 48, p. 603.

77 Ibid., Separate Opinion of Judge Higgins, p. 215, párr. 33. Para un análisis en profundidad de este argumento véase Higgins, R., Problems and Process: International Law and How We Use It, Oxford, Oxford University Press, 1995, pp. 250-251.

${ }_{78}$ Como señaló el Juez Simma en una muy relevante opinión separada en este caso, «la Corte debería haber aprovechado la oportunidad... para clarificar el Estado del Derecho en un asunto muy controvertido que viene marcado por una gran controversia y confusión —en gran parte porque la propia Corte ha contribuido sustancialmente a esta confusión con la sentencia en el caso Nicaragua hace dos décadas-». La postura en torno a que el art. 51 de la Carta de las Naciones Unidas reconoce el derecho de legítima defensa exclusivamente en el caso de un ataque armado de un Estado contra otro Estado «puede haber reflejado... la interpretación que ha prevalecido sobre la legítima defensa durante mucho tiempo. Sin embargo, a la luz de desarrollos recientes no sólo en cuanto a la práctica estatal sino también en el ámbito de la opinio iuris, debería ser reconsiderada urgentemente, también por la Corte. Como es bien sabido, estos desarrollos han sido alentados por los atentados del 11 de septiembre, y a partir de ahí la comunidad internacional ha acogido favorablemente las pretensiones de que el art. 51 también permita medidas defensivas contra grupos terroristas... Las Resoluciones 1368 (2001) y 1373 (2001) no pueden leerse más que como afirmaciones de la postura en torno a que ataques a gran escala por parte de actores no estatales se pueden considerar como "ataques armados" según el significado del art. 51 ", Armed Activities on the Territory of the Congo (Democratic Republic of the Congo v. Uganda), Judgment, ICJ Reports 2005, Separate Opinion by Judge Simma, pp. 336-337, párrs. 8 y 11. 
argumentos de las Partes en cuanto a si, y bajo qué circunstancias, el Derecho internacional contemporáneo reconoce el derecho de legítima defensa frente a ataques a gran escala por parte de fuerzas irregulares ${ }^{79}$. En este caso, el juez Kooijmans también emitió una opinión separada en la que reiteró, con más rotundidad si cabe, la postura expresada en la Opinión Consultiva de 2004. En su opinión, "si los ataques por grupos irregulares, dados su escala y sus efectos, hubieran tenido que ser clasificados como un ataque armado si se hubieran llevado a cabo por las fuerzas armadas regulares, no hay nada en el lenguaje del art. 51 de la Carta que impida al Estado víctima ejercer su derecho inmanente de legítima defensa» ${ }^{80}$. Esta interpretación evolutiva del derecho de legítima defensa frente a ataques de actores no estatales ha encontrado una acogida mayoritaria tanto entre la doctrina como entre los Estados ${ }^{81}$. Como ha señalado en este sentido Andrew C. Orr, «la aquiescencia de la comunidad internacional al uso de la fuerza armada en Afganistán por parte de Estados Unidos tras los atentados del 11 de septiembre sirve para reforzar la postura en torno a que los ataques por actores no estatales pueden justificar el uso de fuerza armada defensiva» ${ }^{82}$.

Una vez admitido que, en principio, los ataques lanzados por grupos terroristas que cruzan un determinado nivel de intensidad pueden llegar a ser considerados excepcionalmente como un ataque armado, y que dichos ataques de un actor no estatal pueden poner en funcionamiento la legítima defensa reconocida en el art. 51 de la Carta de las Naciones Unidas, ahora nos tenemos que detener en las condiciones del ejercicio de dicho derecho de legítima defensa.

En primer lugar, debemos preguntarnos acerca de la situación en la que se encuentra el Estado desde el que se lanzan los ataques terroristas. Todos los Estados cuentan en su patrimonio con el derecho a la inviolabilidad de su territorio, lo que excluye la utilización de la fuerza armada por parte de otro Estado en su territorio sin su consentimiento ${ }^{83}$. Ahora bien, este derecho del Estado no puede convertirse en un paraguas que sirva para amparar situaciones en las que un Estado permita, aliente o incluso contribuya, a acciones de grupos terroristas contra intereses legítimos de terceros Estados.

79 Armed Activities on the Territory of the Congo (Democratic Republic of the Congo v. Uganda), Judgment, ICJ Reports 2005, p. 223, párr. 147.

${ }^{80} \mathrm{Ibid}$., Separate Opinion of Judge Kooijmans, p. 314, párr. 29.

81 Lubell, N., Extraterritorial Use of Force against Non-State Actors, Oxford, Oxford University Press, 2010, p. 260; Melzer, N., op. cit., nota 3, p. 22; BARnidge, R. P., op. cit., nota 17, p. 428; DinsTEIN, Y., op. cit., nota 71, pp. 229-230; SchmitT, M. N., «Targeted Killings and International Law: Law Enforcement, Self-Defense, and Armed Conflict», en ARNOLD, R. y QuÉNIVET, N. (eds.), International Humanitarian Law and Human Rights Law: Towards a New Merger in International Law, Dordrecht, Martinus Nijhoff Publishers, 2008, p. 525. Para una opinión no tan favorable a esta evolución de la legítima defensa véase Remiro Brotons, A., "Terrorismo, mantenimiento de la paz y nuevo orden», Revista Española de Derecho Internacional, vol. LIII, 2001, núms. 1 y 2, pp. 150-157. Como señala este autor, «lo que se propone como interpretación amplia o extensiva del concepto de legítima defensa acaba desnaturalizándolo» (p. 157).

82 OrR, A. C., op. cit., nota 71, p. 740.

83 Art. 2.4 de la Carta de las Naciones Unidas. 
Estas obligaciones de los Estados de prevenir cualquier tipo de actividad terrorista desde su territorio contra otros Estados y de luchar eficazmente contra dichas actividades han adquirido incluso carácter consuetudinario para la Corte Internacional de Justicia ${ }^{84}$. Este planteamiento conduce, según Melzer, a que un Estado que no pueda o no quiera («unable or unwilling») ${ }^{85}$ prevenir el uso de su territorio como base para actividades hostiles contra terceros Estados «pueda tener que tolerar una acción defensiva necesaria y proporcional dentro de su territorio soberano» ${ }^{86}$. Esta postura ha sido criticada por algunos internacionalistas pakistaníes, que consideran que los ataques con drones en su país constituyen una clara "violación de la soberanía de una nación que proclama oficialmente ser un aliado importante en la lucha contra el terrorismo» ${ }^{87}$. Para Dawood Ahmed, no hay ninguna norma convencional que permita una acción armada defensiva en el territorio de un Estado «simplemente porque presuntamente ese Estado no puede o no quiere prevenir potenciales ataques terroristas» ${ }^{88}$. En esta línea, un tribunal de Pakistán ha llegado a dictaminar que

«los ataques con drones en las áreas tribales... por la CIA y por las autoridades norteamericanas constituyen una abierta violación de derechos humanos básicos y de la Carta de las Naciones Unidas... Asimismo, los ataques con drones suponen una violación absolutamente ilegal de la soberanía del Estado de Pakistán, ya que las intrusiones en su territorio y en su espacio aéreo se llevan a cabo

${ }^{84}$ La Corte basa su argumento en la Declaración sobre los Principios de Derecho internacional referentes a las relaciones de amistad y a la cooperación entre los Estados de conformidad con la Carta de las Naciones Unidas, aprobada por la Asamblea General de las Naciones Unidas el 24 de octubre de 1970, Resolución 2625 (XXV). Como dispone esta Declaración, «todo Estado tiene el deber de abstenerse de organizar, instigar, ayudar o participar en actos de guerra civil o en actos de terrorismo en otro Estado o de consentir actividades organizadas dentro de su territorio encaminadas a la comisión de dichos actos, cuando los actos a que se hace referencia en el presente párrafo impliquen el recurrir a la amenaza o al uso de la fuerza» (principio 1, relativo a la abstención de recurrir a la amenaza o al uso de la fuerza). Asimismo, prosigue la Declaración, «todos los Estados deberán también abstenerse de organizar, apoyar, fomentar, financiar, instigar o tolerar actividades armadas, subversivas o terroristas encaminadas a cambiar por la violencia el régimen de otro Estado, y de intervenir en las luchas interiores de otro Estado" (principio 3, relativo a la obligación de no intervenir en los asuntos que son de la jurisdicción interna de los Estados). Como establece la Corte, "estas normas son declaratorias de Derecho internacional consuetudinario", Armed Activities on the Territory of the Congo..., op. cit., nota 79 , p. 227, párr. 162.

85 Para un intento de diferenciar estas dos categorías cuyos contornos y alcance no están siempre claramente definidos véase ReINOLD, T., "State Weakness, Irregular Warfare, and the Right to Self-Defense Post-9/11», American Journal of International Law, vol. 105, 2011, núm. 2, pp. 244-246; DEEKS, A. S., «Unwilling or unable: toward a normative framework for extra-territorial self-defence», Virginia Journal of International Law, vol. 5, 2012, núm. 3, pp. 483-550.

${ }_{86}$ Melzer, N., op. cit., nota 3, p. 22. Éste es el sentido último de las Resoluciones del Consejo de Seguridad 1368 (2001) y 1373 (2001), donde se establecen toda una batería de medidas que todos los Estados tienen que tomar para prevenir y reprimir la financiación y preparación de los actos de terrorismo. Los Relatores Especiales Alston y Heyns también aceptan esta posibilidad de que la legítima defensa se pueda utilizar cuando el Estado desde el que opera el grupo terrorista no quiere o no puede impedir la preparación y el lanzamiento de ataques contra otros Estados, ALsTON, P., op. cit., nota 36, p. 12; HeYNS, C., op. cit., nota 5, pp. 21-22.

87 SHAH, S. A., op. cit., nota 70, pp. 81-82.

88 Ahmed, D., «Rethinking Anti-Drone Legal Strategies: Questioning Pakistani and Yemeni Consent», Yale Journal of International Affairs, vol. 8, 2013, núm. 2, p. 2. 
no sólo sin su consentimiento, sino contra los deseos expresados por el Gobierno de Pakistán ante Estados Unidos...» ${ }^{89}$.

Los dos principios fundamentales que regulan el ejercicio del derecho de legítima defensa son la necesidad y la proporcionalidad ${ }^{90}$, principios que también han adquirido carácter consuetudinario ${ }^{91}$. El principio de necesidad apunta a que el Estado que ha sido atacado, o que está a punto de serlo mediante un ataque inminente ${ }^{92}$, no cuenta con otros medios para repeler o evitar el ataque que el recurso a la fuerza armada. La necesidad nos lleva a otra de las características esenciales del ejercicio de la legítima defensa, como es la inmediatez. La respuesta armada debe ser una respuesta inmediata que pretende contrarrestar los efectos de un ataque armado previo o inminente si realmente se quiere justificar como legítima defensa. En el caso de los atentados terroristas del 11 de septiembre, Pons Rafols y Paniagua señalan que "parece más bien una forma de castigo o de represalia por los atentados sufridos que se pone en marcha tres semanas después de ocurridos los hechos» ${ }^{93}$. La cuestión de la proporcionalidad de la respuesta armada defensiva también resulta problemática, ya que surgen dudas de hasta qué punto es apropiada y proporcional una respuesta de carácter armado a un ataque terrorista. Aunque la respuesta armada fuera proporcional en el caso de los atentados del 11 de septiembre, nos asaltan muchas más dudas cuando la respuesta armada se produce en casos como Yemen o Somalia, donde la gravedad y la intensidad de los ataques terroristas es infinitamente menor. En

89 Peshawar High Court Order, 11 April 2013, Writ Petition No. 1551-P/2012, párr. 22.

90 Para un análisis en profundidad de las condiciones para el ejercicio de la legítima defensa véase Ortega Carcelén, M. C., La legítima defensa del territorio del Estado. Requisitos para su ejercicio, Madrid, Tecnos, 1991.

91 Como señaló la Corte Internacional de Justicia en el caso de las Actividades Militares y Paramilitares en y contra Nicaragua, "there is a specific rule whereby self-defence would warrant only measures which are proportional to the armed attack and necessary to respond to it, a rule well established in customary international law», Military and Paramilitary Activities in and against Nicaragua..., op. cit., nota 63, p. 94, párr. 176. Véase en el mismo sentido Legality of the Threat or Use of Nuclear Weapons, op. cit., nota 53, p. 245, párr. 41.

92 La cuestión de la inminencia del ataque armado nos lleva a otro debate que no vamos a abordar en este artículo por cuestiones de espacio, como es el tema de la legítima defensa preventiva utilizada por la Administración Bush para justificar su polémica «guerra contra el terrorismo». Como establecía la Estrategia sobre Seguridad Nacional aprobada en 2002, «debemos adaptar el concepto de amenaza inminente a las capacidades y los objetivos de los adversarios actuales... Para abortar y prevenir los actos hostiles de nuestros adversarios, los Estados Unidos actuarán, de ser necesario, preventivamente..., incluso teniendo en cuenta la incertidumbre en cuanto a cuándo y dónde atacará el enemigo", The National Security Strategy of the United States of America, September 2002, p. 15, en http://www. state.gov/documents/organization/63562.pdf. Si bien la legítima defensa ante un ataque inminente goza de predicamento tanto en la doctrina como en la práctica de los Estados, en cambio la vaguedad de la legítima defensa preventiva ante supuestos ataques y amenazas que no son inminentes es ampliamente contestada y no cuenta con el apoyo del Derecho internacional, PéREz GonZÁLEz, M, «La legítima defensa puesta en su sitio: observaciones críticas sobre la doctrina Bush de la acción preventiva», Revista Española de Derecho Internacional, vol. LV, 2003, núm. 1, p. 203. Para una opinión no tan desfavorable a la legítima defensa preventiva basada en el Derecho internacional general véase RIPOLL CARULLA, S., «La nueva doctrina global de defensa preventiva. Consideraciones sobre su caracterización y fundamento», en García SEgura, C. y Rodrigo HernándeZ, A. J. (eds.), op. cit., nota 72, pp. 141-164.

93 Pons Rafols, X. y Paniagua Redondo, R., op. cit., nota 70, p. 45. 
todo caso, para poder justificar la utilización de drones alegando la legítima defensa, el ataque terrorista tiene que alcanzar tal grado de intensidad que se pueda considerar como un "ataque armado», sin que sirvan actos terroristas "aislados o de alcance limitado» ${ }^{94}$.

También existen dudas más que justificadas por lo que puede suponer la aceptación del argumento de la legítima defensa para el sistema de seguridad colectiva instaurado en la Carta de las Naciones Unidas para velar por el mantenimiento de la paz y la seguridad internacionales. La respuesta armada defensiva supondría una reacción unilateral por parte de Estados Unidos con un papel del Consejo de Seguridad de las Naciones Unidas como auténtico «convidado de piedra» ${ }^{95}$. Este ejercicio espurio del derecho a la legítima defensa puede acabar dinamitando el sistema de seguridad colectiva establecido en la Carta de las Naciones Unidas con el pretexto de luchar contra el terrorismo ${ }^{96}$.

Podemos concluir, por tanto, que el argumento de la legítima defensa para justificar la utilización de drones en el marco de la lucha contra el terrorismo no deja de resultar problemático. Vamos a analizar a continuación la otra excepción al principio de la prohibición del uso de la fuerza en las relaciones internacionales: el consentimiento del Estado en el que se despliegan los drones.

\subsubsection{El consentimiento del Estado}

El consentimiento válido de un Estado relativo a la utilización de drones en su territorio para asesinatos selectivos en el contexto de la lucha contra el terrorismo excluye la ilicitud del uso de la fuerza armada ${ }^{97}$. Como dispone al respecto el art. 20 del Proyecto de Artículos sobre la Responsabilidad del Estado por hechos internacionalmente ilícitos ${ }^{98}$,

«el consentimiento válido de un Estado a la comisión por otro Estado de un hecho determinado excluye la ilicitud de tal hecho en relación con el primer

94 CASEY-Maslen, S., op. cit., nota 48, p. 605.

95 GonzÁlez Vega, J. A., "Los atentados del 11 de septiembre, la operación "Libertad Duradera" y el derecho de legítima defensa", Revista Española de Derecho Internacional, vol. LIII, 2001, núm. 1, p. 270. Este papel de espectador pasivo del Consejo de Seguridad de las Naciones Unidas se acrecienta si tenemos en cuenta que Estados Unidos no ha informado al Consejo de los ataques con drones bajo la justificación de la legítima defensa, tal y como exige el art. 51 de la Carta de las Naciones Unidas ( «...Las medidas tomadas por los Miembros en ejercicio del derecho de legítima defensa serán comunicadas inmediatamente al Consejo de Seguridad...», la cursiva es nuestra).

96 Joaquín Alcaide se ha referido a la «muerte» de la acción institucional en materia de recurso a la fuerza mediante esta utilización del argumento de la legítima defensa, ALCAIDE FERnÁndEz, J., «La "guerra contra el terrorismo": ¿una "OPA hostil” al Derecho de la comunidad internacional?", Revista Española de Derecho Internacional, vol. LIII, 2001, núm. 1, p. 298.

97 Advisory Committee on Issues of Public International Law, op. cit., nota 40, p. 1. Para un análisis en profundidad de la relevancia del consentimiento en relación con el uso de la fuerza véase DEEKS, A. S., "Consent to the use of force and international law supremacy", Harvard International Law Journal, vol. 54, 2013, núm. 1, pp. 1-60.

98 Resolución 56/83, Asamblea General de las Naciones Unidas, 12 de diciembre de 2001. 
Estado en la medida en que el hecho permanece dentro de los límites de dicho consentimiento».

Ahora bien, el consentimiento no convierte automáticamente en legal el ataque con drones ${ }^{99}$. En primer lugar, en ningún caso se podría consentir la violación de una norma imperativa de Derecho internacional general, como el derecho a la vida por ejemplo ${ }^{100}$. Éste es el sentido del art. 26 del Proyecto de Artículos que acabamos de citar cuando establece que «ninguna disposición del presente capítulo excluirá la ilicitud de cualquier hecho de un Estado que no esté de conformidad con una obligación que emana de una norma imperativa de Derecho internacional general». Por otro lado, aunque el ataque con drones no vulnere la soberanía del Estado donde tiene lugar y, por tanto, no sea ilícito porque este consiente, habrá que analizar en cada caso concreto su legalidad desde el punto de vista bien del DIH, bien del DIDH, en función de cuál de estos dos regímenes resulte aplicable, como veremos posteriormente.

Estas limitaciones al alcance del consentimiento llevan a algunos a defender que el Estado que consiente la utilización de drones en su territorio tendría la obligación de imponer condiciones bastante estrictas a dicha utilización. Como ha señalado Philip Alston a este respecto, el Estado que consiente debería, «como mínimo, exigir al Estado que va a utilizar drones que le demuestre que la persona contra la que se va a utilizar fuerza letal es un objetivo legítimo» ${ }^{101}$. Además, después de cada asesinato selectivo con drones, «el Estado que dio el consentimiento debería asegurarse de que fue legal y, en caso de duda, investigar» ${ }^{102}$. Y, por último, si de esa investigación se deduce que el asesinato selectivo no cumplió con todos los requisitos legales, el Estado que consintió «debería procesar a los presuntos culpables y compensar a las víctimas» ${ }^{103}$. Lo cierto es que todos los indicios apuntan a que el consentimiento para la utilización de drones suele ser un cheque en blanco que deja todo en manos de la discrecionalidad del Estado que los utiliza, sobre todo cuando es un Estado tan poderoso y con tanta influencia en los países que consienten como Estados Unidos ${ }^{104}$.

Los casos en los que todo parece indicar que los Estados en cuyo territorio se utilizaron drones consintieron son Yemen y Pakistán. En el caso de Yemen no hay dudas, ya que hay evidencias en torno a que desde las más altas instancias gubernamentales se otorgó el consentimiento para utilizar drones por parte de Estados Unidos en la lucha contra Al-Qaeda in the Arabian Peninsula (AQAP), la rama local de Al-Qaeda ${ }^{105}$. El propio Relator Especial sobre Te-

99 Benjamin, M., op. cit., nota 4, p. 143.

100 Heyns, C., op. cit., nota 5, p. 9.

101 Alston, P., op. cit., nota 36, p. 12.

102 Ibid.

103 Ibid.

104 Esta situación lleva a algunos incluso a afirmar que «es razonable defender que Estados Unidos puede haber coaccionado a Estados como Pakistán o Yemen, Estados muchísimo más débiles, para que consientan» (la cursiva es del autor), AHMED, D., op. cit., nota 88, p. 5.

105 Jordán, J., "La campaña de ataques con drones en Yemen», Revista del Instituto Español de Estudios Estratégicos, 2013, núm. 1, p. 47. 
rrorismo y Derechos Humanos ha recibido confirmación oficial por parte del Gobierno de Yemen de que Estados Unidos solicita su consentimiento para cada operación letal con drones dentro de su territorio ${ }^{106}$.

En el caso de Pakistán, la cuestión del consentimiento se complica ante los vaivenes y los cambios de postura adoptados por el Gobierno en relación con el uso de los drones. De nuevo hay evidencias más que suficientes para demostrar que, por lo menos hasta 2012, los sucesivos presidentes de Pakistán otorgaron su consentimiento a la utilización de drones en su territorio ${ }^{107}$, aunque en ocasiones lo negaran públicamente debido a la creciente oposición a los drones por parte de la opinión pública pakistaní. Esta situación comienza a cambiar dramáticamente por dos acontecimientos que supusieron un notable enfriamiento de las relaciones bilaterales entre Estados Unidos y Pakistán. Nos referimos, en primer lugar, a la operación de las fuerzas especiales norteamericanas (JSOC, Joint Special Operations Command) en Abbottabad (Pakistán) en mayo de 2011 que puso fin a la vida de Bin Laden y, en segundo lugar, a la muerte por error de 24 soldados pakistaníes en un ataque aéreo de la OTAN ${ }^{108}$. Lo cierto es que estos hechos contribuyeron no sólo a enturbiar las relaciones entre los dos países, sino que motivaron un cambio de postura radical en relación con el uso de los drones. Fruto de ello, las dos cámaras del Parlamento pakistaní aprobaron una Resolución el 12 de abril de 2012 en la que, entre otras cosas, solicitaban un cese inmediato de los ataques con drones dentro de sus fronteras ${ }^{109}$. Desde entonces esta postura no ha cambiado, habiendo sido incluso confirmada por un tribunal pakistaní, $\operatorname{como~vimos}^{110}$. Como señala al respecto el Relator Especial sobre Terrorismo y Derechos Humanos, Ben Emmerson, la nueva Administración surgida de las elecciones de mayo de 2013 sigue manteniendo que el uso de los drones en la zona de Waziristán «es contraproducente, contrario al Derecho internacional, una violación de la soberanía pakistaní y, en consecuencia, debe cesar inmediatamente» ${ }^{111}$. Por tanto, concluye el Relator, el uso de los drones en Pakistán supondría una «violación de la soberanía pakistaní, salvo que se justifique acudiendo a la legítima defensa» ${ }^{112}$.

Una vez analizados los problemas que suscita la utilización de los drones desde la perspectiva del ius ad bellum, ahora toca abordarlos desde la óptica del DIH.

106 Emmerson, B., Report of the Special Rapporteur on the promotion and protection of human rights and fundamental freedoms while countering terrorism, UN Doc. A/68/389, 18 September 2013, p. 15.

107 Casey-Maslen, S., "Drone Strikes in Pakistan in 2012», en Casey-Maslen, S. (ed.), The War Report 2012, Oxford, Oxford University Press, 2013, p. 228.

108 «US admits mistakes over killings of Pakistan troops», BBC, 22 December 2011, en http://www. bbc.co.uk/news/world-asia-16302197.

109 MASOOD, S. y WALSH, D., "Pakistan Gives U.S. a List of Demands, Including an End to CIA Drone Strikes», The New York Times, 13 April 2012, p. A6, en http://www.nytimes.com/2012/04/13/world/ asia/pakistan-demands-an-end-to-cia-drone-strikes.html.

110 Peshawar High Court Order, op. cit., nota 89.

111 Emmerson, B., op. cit., nota 106, p. 15.

112 Ibid. 


\subsection{Los drones ante el ius in bello}

\subsubsection{La existencia de un "conflicto armado"}

Uno de los requisitos indispensables para que podamos aplicar las normas del DIH es que estemos en presencia de una situación de "conflicto armado», término cuyos contornos no están totalmente clarificados ${ }^{113}$. Si no nos encontramos ante un conflicto armado, entonces resultarán de aplicación las normas del DIDH, de carácter mucho más protector en cuanto a quién puede considerarse como un objetivo legítimo de un ataque selectivo con drones y bajo qué condiciones se puede llevar a cabo dicho ataque.

La emergencia de la denominada guerra contra el terrorismo tras los atentados del 11 de septiembre ha venido a trastocar alguna de las categorías básicas del DIH, como la propia definición de conflicto armado. En este sentido, tanto la Administración Bush como la Administración Obama consideran que el conflicto con la red terrorista Al-Qaeda es un conflicto armado y que, por tanto, el régimen que resulta aplicable es el DIH. Ello ha conducido a una «aplicación expansiva del DIH a cualquier operación antiterrorista, independientemente de si los requisitos exigidos para estar ante un conflicto armado se cumplen o no» ${ }^{114}$. Y debemos reconocer que las normas del DIH son mucho más permisivas que las del DIDH en lo concerniente a quién puede considerarse como un objetivo legítimo de un ataque con drones, lo que puede convertirse en una auténtica tentación para algunos Gobiernos. Como ha señalado Philip Alston con cierta preocupación, estamos asistiendo a una imparable tendencia "a expandir quién puede ser objetivo legítimo de un ataque y bajo qué condiciones» ${ }^{15}$, lo que puede acabar otorgando una «vagamente definida licencia para matar» ${ }^{116}$.

Uno de los puntos más polémicos de la actual lucha contra el terrorismo es la cuestión de los límites geográficos y si hemos asistido a la emergencia de lo que se denomina un "campo de batalla global» ${ }^{117}$. La postura oficial de Estados Unidos es que el conflicto armado con Al-Qaeda no puede contar con límites territoriales definidos, dada la ubicuidad transnacional con la que opera la red terrorista Al-Qaeda. El establecer límites territoriales estrictos a la existencia de un conflicto armado y, por tanto, a la aplicación del DIH, supondría la creación de santuarios desde los que seguir atacando y territorios seguros para los terroristas por el mero hecho de cruzar una frontera ${ }^{118}$. A pesar de que el concepto de "campo de batalla global» no cuenta con respaldo jurídico internacional, sí que es posible aceptar una cierta extensión de

113 O'Connell, M. E., «Defining Armed Conflict», Journal of Conflict \& Security Law, vol. 13, 2008, núm. 3, p. 393.

114 Melzer, N., op. cit., nota 3, p. 20.

115 Alston, P., op. cit., nota 36, p. 3.

116 Ibid.

117 BLANK, L. R., op. cit., nota 28, p. 711.

118 LEWIS, M. W., op. cit., nota 26, p. 312. 
los límites geográficos de un determinado conflicto armado para prevenir, precisamente, la evasión de la aplicación del DIH. Pero para que ello sea posible tiene que haber un «nexo» ${ }^{119}$, una «relación sustancial» ${ }^{120}$ entre el conflicto armado original y las actividades llevadas a cabo más allá de los límites geográficos de ese conflicto. Este vínculo es un elemento esencial que hay que determinar en relación con el uso de drones en la actual lucha contra el terrorismo, ya que «no siempre está claro si los individuos asesinados selectivamente son de hecho miembros de los mismos grupos armados contra los cuales Estados Unidos está luchando en Afganistán» ${ }^{121}$. Esto nos lleva a considerar que las hostilidades entre Estados Unidos y grupos de la red terrorista Al-Qaeda en la zona fronteriza de Waziristán en Pakistán forman parte del mismo conflicto armado que tiene lugar en Afganistán, por lo que resultaría aplicable el DIH. En cambio, es mucho más dudoso que las operaciones con drones en Somalia o Yemen se puedan considerar como parte del mismo conflicto armado. Entonces habría que demostrar que las hostilidades en estos países constituyen un conflicto armado entre los grupos terroristas y Somalia o Yemen si queremos que resulte de aplicación el DIH en lugar del DIDH.

El DIH distingue entre dos tipos de conflicto armado, el conflicto armado internacional y el conflicto armado no internacional, «aunque dibujar una línea de demarcación clara entre ellos no sea una tarea tan sencilla como parece a primera vista» ${ }^{122}$. No existe ninguna otra categoría, aunque ha habido intentos por parte de Estados Unidos de ampliar esta tipología para incluir la guerra contra el terrorismo como conflicto armado de carácter transnacional o global, algo que ha sido desechado ampliamente por la doctrina ${ }^{123}$. Como ha puesto de manifiesto Amnistía Internacional en un informe sobre los drones en Pakistán, no es aceptable la idea de que el Derecho internacional le permita a Estados Unidos «involucrarse en un conflicto armado de alcance global contra una difusa red de actores no estatales o que sea legal asesinar selectivamente individuos en cualquier lugar y en cualquier momento en que Estados Unidos lo considere apropiado» ${ }^{124}$. Lo cierto es que no es necesaria una nueva categoría, ya que ciertos componentes de la guerra contra el terrorismo sí se podría considerar que caen bajo el paraguas de un conflicto armado no internacional, como por ejemplo las hostilidades entre Al-Qaeda y Estados Unidos en Afganistán e, incluso, en determinadas zonas

119 Lubell, N. y Derejko, N., "A Global Battlefield? Drones and the Geographical Scope of Armed Conflict», Journal of International Criminal Justice, vol. 11, 2013, p. 75.

120 BARnidge, R. P., op. cit., nota 17, p. 438.

121 Lubell, N. y DereJKo, N., op. cit., nota 119, p. 77.

122 Dinstein, Y., op. cit., nota 57, p. 26. Tradicionalmente, los conflictos armados internacionales son aquellos conflictos armados que tienen lugar entre Estados, mientras que los conflictos armados no internacionales son aquellos que tienen lugar entre Estados y grupos armados en el territorio de uno o de varios Estados.

123 Bhuta, N., op. cit., nota 1, p. 259; STERIo, M., op. cit., nota 12, p. 204. Sin embargo, hay otros autores que defienden la pertinencia de mantener una distinción conceptual entre las guerras civiles internas y los conflictos armados transnacionales como el que supone la guerra contra el terrorismo, LEWIS, M. W., op. cit., nota 26, p. 307.

124 AmNesty INTERNATIONAL, op. cit, nota 21, p. 48. 
de Pakistán ${ }^{125}$. En cambio, las hostilidades en otros escenarios como Yemen o Somalia encajan con mayores dificultades en lo que se entiende como un conflicto armado.

Durante mucho tiempo el DIH ha sido incapaz de ofrecer una definición satisfactoria de lo que se puede considerar como un "conflicto armado». Ni las Convenciones de Ginebra ni sus Protocolos Adicionales zanjaban esta indefinición. En los últimos años hemos asistido a un interesante proceso de clarificación, siendo la culminación la definición aportada por la International Law Association (ILA) en 2010. En su cualificada opinión, «al menos dos características se encuentran presentes en todos los conflictos armados: 1) la existencia de grupos armados organizados, y 2) involucrados en una lucha de cierta intensidad» ${ }^{126}$.

Aquí también surgen dudas en torno hasta qué punto la red terrorista Al-Qaeda es realmente un grupo armado con un suficiente grado de organización y de coordinación, y si tiene capacidad para involucrarse en ataques de una envergadura e intensidad suficientes como para considerarse ataques $\operatorname{armados}^{127}$. Si bien hasta 2001 se puede argumentar que Al-Qaeda podía considerarse "como un grupo organizado con un claro liderazgo e incluso una localización fija» ${ }^{128}$, la invasión de Afganistán por parte de Estados Unidos «precipitó la dispersión física del grupo y la transición hacia una red descentralizada de grupos e individuos operando sobre la base de una ideología compartida» ${ }^{129}$. Los atentados posteriores en Bali, Madrid o Londres es mucho más difícil vincularlos y atribuirlos a un único grupo terrorista, «aunque los perpetradores parecen haberse inspirado en la ideología de Al-Qaeda» ${ }^{130}$. Comparto la conclusión de Noam Lubell en el sentido de que «si estos incidentes han sido llevados a cabo por grupos separados sin una dirección unificada y organizada y sin una estructura de control, entonces es mucho más difícil sumarlos todos como evidencia de un conflicto armado previo» ${ }^{131}$. En consecuencia, si esas acciones no cruzan el umbral de lo que se considera

125 Lubell, N., op. cit., nota 81, p. 120.

126 Final Report on the Meaning of Armed Conflict in International Law, International Law Association, The Hague Conference, 2010, p. 2. La propia ILA se reconoce tributaria de la definición elaborada por el Tribunal Penal para la antigua Yugoslavia en el famoso caso Tadic de 1995, una definición que ya se refería a los criterios de organización e intensidad, Prosecutor v. Tadic, caso núm. IT-94-1-T, 1995.

127 Para un análisis en profundidad de los orígenes y la evolución de Al-Qaeda véase JonES, S. G., Hunting in the Shadows. The Pursuit of Al Qa'Ida since 9/11, Nueva York, W. W. Norton \& Company, 2013.

128 LubELl, N., op. cit., nota 81, p. 118.

129 Ibid.

130 Ibid., p. 119. En relación con el atentado en los trenes de cercanías en Madrid el 11 de marzo de 2004, Fernando Reinares cuestiona lo que él denomina las teorías de «una yihad sin líder». En su opinión, existen sobradas evidencias para demostrar que el atentado fue, en realidad, «una expresión temprana a la vez que compleja de las capacidades con que podía llegar a contar Al Qaeda en Europa occidental dos años y medio después del 11-S», ReINARES, F., "Venganza cumplida», El País (monográfico «11 Miradas sobre el 11-M»), 9 de marzo de 2014, p. 6. Para un análisis mucho más profundo véase ReInAREs, F., ¡Matadlos! Quién estuvo detrás del 11-M y por qué se atentó en España, Madrid, Galaxia Gutenberg, 2014.

131 LubELL, N., op. cit., nota 81, p. 120. 
como un conflicto armado, su regulación no caería bajo el DIH, sino que el régimen aplicable sería el DIDH.

\subsubsection{Los principios de distinción, proporcionalidad, necesidad militar y humanidad}

Si nos encontramos en el marco de un conflicto armado, todo ataque con drones debe respetar los principios básicos del DIH como son los principios de distinción, proporcionalidad, necesidad militar y humanidad. Ahora bien, el análisis en torno a si los ataques con drones por parte de Estados Unidos respetan o no estos principios está muy condicionado por una absoluta falta de transparencia en cuanto a los criterios que justifican el uso de asesinatos selectivos con drones, los procedimientos que se siguen al respecto y las investigaciones que llevan a cabo las autoridades norteamericanas, si es que las llevan, para determinar si las operaciones son exitosas o, en cambio, pueden quedar empañadas por daños colaterales entre la población civil ${ }^{132}$. Obviamente, a ello no ayuda en absoluto que la mayor parte de las operaciones con drones sean llevadas a cabo por la CIA, con una sórdida historia de secretismo y de operaciones encubiertas bordeando, o traspasando directamente, la legalidad ${ }^{133}$.

Un principio absolutamente básico que ha adquirido el carácter de norma consuetudinaria es la distinción entre población civil y población combatiente $^{134}$, siendo esta última la única que puede ser objeto legítimo de un ataque. Lo cierto es que el respeto del principio de distinción es especialmente problemático, dado que los grupos terroristas se entremezclan con la población civil como parte de su estrategia. La población civil pierde su protección especial cuando "participan directamente en las hostilidades y mientras dure tal participación» ${ }^{135}$. Es decir, una persona que esté participando directamente en las hostilidades puede considerarse como un objetivo legítimo de un ataque con drones. De todas maneras, no existe una definición de «participación directa en las hostilidades» en el DIH ni en la práctica de los Estados, lo que ha dado lugar a dudas y ambigüedades en relación con quiénes pueden ser un objetivo legítimo de un ataque con drones. Tal y como señala el Comité Internacional de la Cruz Roja (CICR), la noción de participación directa en las hostilidades se refiere a «actos hostiles específicos llevados

132 Alston, P., op. cit., nota 36, p. 26.

133 Amnesty International, op. cit, nota 21, p. 49.

134 Como establece el art. 48 del Protocolo I Adicional a los Convenios de Ginebra de 1949 relativo a la protección de las víctimas de los conflictos armados internacionales, «a fin de garantizar el respeto y la protección de la población civil y de los bienes de carácter civil, las Partes en conflicto harán distinción en todo momento entre población civil y combatientes...». Por su parte, el Protocolo II Adicional a los Convenios de Ginebra de 1949 relativo a la protección de las víctimas de los conflictos armados sin carácter internacional dispone en su art. 13.2 que «no serán objeto de ataque la población civil como tal, ni las personas civiles».

135 Art. 13.3 del Protocolo II Adicional. Véase, en idéntico sentido, el art. 51.3 del Protocolo I Adicional. 
a cabo por individuos como parte de la conducción de las hostilidades entre partes de un conflicto armado» ${ }^{136}$. El requisito más importante para que se pueda considerar que una persona participa directamente en las hostilidades es que haya un vínculo (nexo beligerante) entre las actividades que lleva a cabo una determinada persona o un grupo de personas y el desarrollo de las hostilidades. En consecuencia, solamente se considerarían como participación directa en las hostilidades aquellas acciones que apoyan directamente el combate, mientras que «acciones más atenuadas tales como el proporcionar ayuda financiera o tareas de propaganda ${ }^{137}$ no entrarían dentro de esa categoría, por lo que sus responsables no podrían ser un objetivo legítimo de un ataque con drones.

Por su parte, los miembros de los grupos armados organizados dejan de ser civiles mientras sigan siendo miembros en virtud de lo que el CICR denomina «función continua de combate» (continuous combat function), por lo que se consideran como objetivos legítimos mientras dure su condición de miembros del grupo armado ${ }^{138}$.

Como vimos en su momento, dada la notable precisión de los drones y su capacidad de vigilancia durante largos periodos de tiempo, pueden estar en condiciones privilegiadas para garantizar el principio de distinción y la protección debida a la población civil ${ }^{139}$, lo cual no quiere decir que necesariamente tenga que ser así. De hecho, la práctica generalizada de los denominados signature strikes hace que planeen serias dudas acerca de la compatibilidad de la utilización de los drones por parte de Estados Unidos con el principio de distinción. Los ataques basados en imprecisos patrones de comportamiento, y no en la participación directa en las hostilidades o en la condición de miembro de un grupo armado, no sólo constituyen una brecha en la línea de flotación del principio de distinción, sino que quedan muy lejos «de las precauciones y presunciones que se deben aplicar en caso de duda» ${ }^{140}$.

La proporcionalidad de un ataque depende de la importancia militar del objetivo. Tal y como establece el art. 51.5.b) del Protocolo I Adicional a los Convenios de Ginebra, se consideran ataques indiscriminados y, por tanto, quedan prohibidos, "cuando sea de prever que causarán incidentalmente muertos y heridos entre la población civil, o daños a bienes de carácter civil, o ambas cosas, que serían excesivos en relación con la ventaja militar concreta

136 ICRC, Interpretive Guidance on the Notion of Direct Participation in Hostilities under International Humanitarian Law, Ginebra, ICRC, mayo de 2009, p. 45. Para que un acto se pueda calificar como participación directa en las hostilidades debe cumplir tres criterios acumulativos: 1) Umbral del daño: el acto debe ser de tal naturaleza que pueda afectar a las capacidades o a las operaciones militares de una de las partes en el conflicto; 2) Causalidad directa: debe existir un nexo causal entre el acto y el daño que previsiblemente va a causar dicho acto, y 3) Nexo beligerante: el acto debe estar específicamente dirigido a causar el umbral del daño exigido, ibid., p. 46.

137 ALston, P., op. cit., nota 36, p. 19.

138 ICRC, op. cit., nota 136, p. 72.

139 Kramer, C., op. cit., nota 27, p. 381.

140 Melzer, N., op. cit., nota 3, p. 23. 
y directa prevista». Por ende, como vemos, no se excluyen totalmente los daños colaterales, pero tienen que ser proporcionales con la ventaja militar que se espera conseguir. Es decir, en cada ataque con drones se deberá llevar a cabo un análisis muy cuidadoso de la ventaja militar que supone un determinado objetivo en relación con los daños incidentales que previsiblemente va a causar dicho ataque. En este punto, debemos reconocer que, a pesar de que no contamos con datos totalmente fiables, los daños colaterales asociados a algunos de los ataques con drones nos hacen dudar seriamente de que hayan sido ataques respetuosos del principio de proporcionalidad ${ }^{141}$.

Por último, los principios de necesidad militar y de humanidad son principios complementarios a la hora de limitar la discrecionalidad de las partes en un conflicto ${ }^{142}$. El principio de necesidad militar permite solamente el uso de aquella fuerza que sea necesaria para alcanzar los objetivos legítimos del conflicto. Y recordemos que el objetivo de un conflicto no es acabar sistemáticamente con el adversario, sino «la sumisión del enemigo de la manera más rápida posible y con el mínimo gasto de vidas humanas y de recursos» ${ }^{143}$. Por su parte, el principio de humanidad establece la prohibición de «armas, proyectiles, materia y métodos de hacer la guerra de tal índole que causen males superfluos o sufrimientos innecesarios» ${ }^{144}$.

\subsection{Los drones ante el DIDH}

Cuando no nos encontramos en una situación de conflicto armado, el régimen que resulta de aplicación al uso de drones para ataques selectivos es el DIDH, un ordenamiento mucho más estricto y menos permisivo que el relativo a los conflictos armados. Es por ello que algunos Estados se suelen mostrar reacios a aplicar estas normas, sobre todo cuando operan fuera de su territorio ${ }^{145}$, ya que consideran que restringe su margen de maniobra en la lucha contra el terrorismo ${ }^{146}$.

Además del Pacto Internacional de derechos civiles y políticos y de las normas de los sistemas regionales que resulten de aplicación en cada caso,

\footnotetext{
141 Véanse los comentarios vertidos en la sección 2.3 de este artículo.

142 ICRC, op. cit., nota 136, p. 79.

143 Ministry of Defence of the United Kingdom, The Manual of the Law of Armed Conflict, Oxford, Oxford University Press, 2004, section 2.2.

144 Art. 35.2 del Protocolo Adicional I a los Convenios de Ginebra. Este principio viene completado con las precauciones que son necesarias tener en cuenta en todo ataque armado, como señala el art. 57 del Protocolo Adicional I. Como señala el párr. 1 del art. 57 de este Protocolo, «las operaciones militares se realizarán con un cuidado constante de preservar a la población civil, a las personas civiles y a los bienes de carácter civil».

145 A pesar del intenso debate tanto doctrinal como jurisprudencial acerca de la aplicación extraterritorial de los tratados de derechos humanos, lo cierto es que, como subraya Melzer, «el asesinato selectivo de individuos mediante ataques extraterritoriales con drones se considerará con toda probabilidad que pone a esos individuos dentro de la jurisdicción del Estado que lanza el ataque», MELzER, N., op. cit., nota 3, p. 18.

146 Melzer, N., Targeted Killing in International Law, Oxford, Oxford University Press, 2008, p. 424.
} 
hay dos normas de soft law que establecen un régimen específico para el uso de la fuerza armada en contextos de aplicación de la ley (law enforcement). Me refiero al Código de Conducta para funcionarios encargados de hacer cumplir la ley (1979) ${ }^{147}$ y a los Principios Básicos sobre el Empleo de la Fuerza y de Armas de Fuego por los funcionarios encargados de hacer cumplir la ley (1990) ${ }^{148}$. Como dispone el art. 3 del Código de Conducta, «los funcionarios encargados de hacer cumplir la ley podrán usar la fuerza sólo cuando sea estrictamente necesario y en la medida que lo requiera el desempeño de sus tareas» (la cursiva es nuestra). Como vemos, a diferencia de lo que ocurría bajo el principio de la necesidad militar en el DIH, aquí el uso de la fuerza es auténticamente excepcional, se trata de la ultima ratio cuando no hay otra manera de detener el peligro inminente para la vida que puede suponer una determinada persona ${ }^{149}$. Por tanto, el asesinato selectivo de un presunto terrorista con drones será ilegal si desde el inicio de la operación ese era el objetivo; bajo el paradigma de los derechos humanos no se puede eliminar a una persona si es posible su captura, precisamente algo que impide un ataque con drones ${ }^{150}$. Lo cierto es que si el programa de drones de Estados Unidos se mira desde el prisma del DIDH, debemos llegar a la conclusión de que su legalidad es más que dudosa ${ }^{151}$. A este respecto, son muy significativas las palabras del anterior Relator Especial sobre ejecuciones extrajudiciales, sumarias o arbitrarias, Philip Alston: "Fuera de un conflicto armado, el uso de drones para asesinatos selectivos casi nunca va a ser legal» ${ }^{152}$.

\section{CONCLUSIONES}

La revolución tecnológica también está afectando a la manera como se usa la fuerza por parte de los Estados. Uno de los avances tecnológicos más relevantes tiene que ver con el creciente uso de aviones no tripulados por parte de Estados Unidos para llevar a cabo asesinatos selectivos en el marco de la lucha contra el terrorismo, lo que plantea notables retos tanto desde el punto de vista ético como desde el plano estrictamente jurídico. Los drones no constituyen per se un arma de carácter indiscriminado, por lo que no re-

147 Asamblea General de las Naciones Unidas, Resolución 34/169, de 17 de diciembre de 1979.

148 Aprobados por el Octavo Congreso de las Naciones Unidas sobre Prevención del Delito y Tratamiento del Delincuente, La Habana, de 27 de agosto a 7 de septiembre de 1990.

149 Como establecen los Principios Básicos sobre el Empleo de la Fuerza, los funcionarios «utilizarán en la medida de lo posible medios no violentos antes de recurrir al empleo de la fuerza y de armas de fuego. Podrán utilizar la fuerza y armas de fuego solamente cuando otros medios resulten ineficaces o no garanticen de ninguna manera el logro del resultado previsto» (principio 4).

150 Véase al respecto Klaidman, D., Kill or Capture. The War on Terror and the Soul of the Obama Presidency, Nueva York, Mariner Books, 2012.

151 Para Melina Sterio, dada la naturaleza del programa de drones de Estados Unidos, utilizado para neutralizar operativos de Al-Qaeda «incluso cuando tales asesinatos no son absolutamente necesarios», es contrario al DIDH, STERIO, M., op. cit., nota 12, p. 205.

152 Alston, P., op. cit., nota 36, p. 25. Véase en la misma línea SADAT, L. N., "America's Drone Wars», Case Western Reserve Journal of International Law, vol. 45, 2012, núms. 1 y 2, p. 225. 
sultan prohibidos por el DIH. Ahora bien, en un contexto de conflicto armado su utilización debe estar regida en todo momento por una aplicación escrupulosa de los principios de distinción, proporcionalidad, necesidad militar y humanidad. Si bien los drones, dadas sus características técnicas relacionadas con la precisión, pueden suponer un acicate para el cumplimiento de estos principios, algunos datos resultantes de su utilización en la práctica nos obligan a acercarnos a ellos con una gran cautela. Tanto el elevado número de víctimas civiles como la mayor propensión a "eliminar» a presuntos terroristas con los ataques con drones, aunque en ocasiones no responda al criterio de la necesidad militar, arroja algunas dudas significativas respecto de su utilización. Estas dudas se acrecientan cuando no nos encontramos en el marco de un conflicto armado. Debemos reconocer que en los supuestos en los que resulta de aplicación el DIDH, un ataque con drones para eliminar a un supuesto terrorista es mucho más difícil de justificar, ya que tiene que ser un ataque estrictamente necesario y responder al criterio de la ultima ratio, es decir, que no existan otros medios para la captura e interceptación del supuesto terrorista.

Por tanto, si bien somos conscientes de que los drones han venido para quedarse y se van a convertir en un ingrediente común en los conflictos contemporáneos y en la lucha contra el terrorismo, su utilización no deja de plantear dilemas bastante serios. Este artículo tan sólo ha esbozado algunos de ellos.

\section{RESUMEN}

\section{LOS ATAQUES ARMADOS CON DRONES EN DERECHO INTERNACIONAL}

La creciente utilización de aparatos aéreos no tripulados, conocidos popularmente como drones, en el marco de la lucha contra el terrorismo, está planteando algunos serios interrogantes tanto desde el punto de vista ético como desde el prisma del Derecho internacional. Debemos reconocer que los drones se han convertido en un elemento estratégico clave dada la naturaleza asimétrica de la mayor parte de los conflictos contemporáneos y dadas las ventajas asociadas a su utilización. Todo ello apunta a que la extensión del uso de drones con fines militares es un proceso de carácter irreversible. El presente artículo tiene por objeto analizar las principales cuestiones jurídico-internacionales planteadas por la utilización de los drones por parte de Estados Unidos en teatros de operaciones tan distintos como Afganistán, Irak, Pakistán, Yemen o Somalia. Mientras que la primera parte del artículo está destinada a describir los pros y los contras de la creciente utilización de drones en los conflictos armados contemporáneos, en la segunda abordamos los principales interrogantes de carácter jurídico-internacional. Así, analizamos la legalidad de los drones como arma de guerra per se, su legalidad desde el punto de vista del ius ad bellum y del ius in bello para, por último, entrar de lleno en su consideración desde la óptica del Derecho internacional de los derechos humanos.

Palabras clave: drones, Derecho internacional, uso de la fuerza, legítima defensa, ius ad bellum, Derecho internacional humanitario, Derecho internacional de los derechos humanos. 


\section{ABSTRACT \\ ARMED ATTACKS WITH DRONES UNDER INTERNATIONAL LAW}

The increasing use of unmanned aerial vehicles (UAVs), also known as drones, in the framework of the war on terror is posing serious challenges both from an ethical and from an international legal perspective. We must accept that drones have become a strategic tool, given the asymmetrical nature of contemporary conflicts and the advantages of their use. In fact, their use for military purposes is an irreversible process. This paper aims to explore the main legal issues raised by the United States use of drones in places such as Afghanistan, Iraq, Pakistan, Yemen and Somalia. While the first part of the paper assesses the pros and cons of the use of drones in contemporary conflicts, the second deals with the legal implications. Thus we analyze the use of drones as a weapon per se, their legality from the angle of both ius ad bellum and ius in bello, and, finally, from the perspective of International Human Rights Law.

Keywords: drones, International Law, use of force, self-defence, ius ad bellum, International Humanitarian Law, International Human Rights Law.

\section{RÉSUMÉ}

\section{LES ATTAQUES ARMÉES AVEC DES DRONES EN DROIT INTERNATIONAL}

L'utilisation d'aéronefs télécommandés (plus couramment connus sous le nom de drones) dans le cadre de la lutte contre le terrorisme a pris une ampleur croissante qui pose de graves questions éthiques et du point de vue du Droit international. Les drones sont devenus, il faut le reconnaître, un élément stratégique clé, et cela est dû au caractère asymétrique de la plupart des conflits actuels et aux avantages qu'entraîne leur usage. Tout signale que la propagation des drones militaires est un processus irréversible. Cet article a pour objet l'analyse des principales questions juridico-internationales posées par l'utilisation des drones par les États-Unis dans des théâtres d'opérations aussi divers que l'Afghanistan, l'Irak, le Pakistan, le Yémen ou la Somalie. Tout d'abord, l'article examine les avantages et les inconvénients de l'utilisation des drones dans les conflits armés actuels. Ensuite, il aborde les principales questions à caractère juridico-international. La légalité des drones en tant qu'arme de guerre per se sera d'abord remise en cause et puis, après avoir révisé leur légalité du point de vue du jus ad bellum et du jus in bello, ils seront examinés dans le cadre du Droit international des Droits de l'Homme.

Mots-clés: drones, Droit international, recours à la force, défense légitime, jus ad bellum, Droit international humanitaire, Droit international des Droits de l'Homme. 